\title{
Process simulation of blue hydrogen production by upgraded sorption enhanced steam methane reforming (SE-SMR) processes
}

\author{
Yongliang Yan $^{1}$, Dhinesh Thanganadar ${ }^{1}$, Peter T. Clough*, Sanjay Mukherjee, Kumar \\ Patchigolla Vasilije Manovic, Edward J. Anthony \\ Energy and Power Theme, School of Water, Energy and Environment, Cranfield University, Cranfield, Bedfordshire, MK43 0AL, \\ UK. \\ ${ }^{1}$ Both authors contributed equally to this work. \\ * Corresponding author: Peter T. Clough, Email: P.T.Clough@cranfield.ac.uk, Phone: +44(0)1234 754873
}

\begin{abstract}
Clean and carbon-free hydrogen production is expected to play a vital role in future global energy transitions. In this work, six process arrangements for sorption enhanced steam methane reforming (SESMR) are proposed for blue $\mathrm{H}_{2}$ production: 1) SE-SMR with an air fired calciner, 2) SE-SMR with a Pressure Swing Adsorption (PSA) unit, 3) SE-SMR thermally coupled with Chemical-Looping Combustion (CLC), 4) SE-SMR+PSA+CLC, 5) SE-SMR+PSA with an oxy-fired calciner, 6) SE-SMR+PSA and indirect firing $\mathrm{H}_{2}$ combustion from the product stream recycle. The proposed process models with rigorous heat exchanger network design were simulated in Aspen Plus to understand the thermodynamic limitations in achieving the maximum $\mathrm{CH}_{4}$ conversion, $\mathrm{H}_{2}$ purity, $\mathrm{CO}_{2}$ capture efficiency, cold gas efficiency and net operating efficiency. A sensitivity study was also performed for changes in the reformer temperature, pressure, and steam to carbon (S/C) ratio to explore the optimal operating space for each case. The SE$\mathrm{SMR}+\mathrm{PSA}+\mathrm{H}_{2}$ (Case 6$)$ recycle process can achieve a maximum of $94.2 \%$ carbon capture with a trade-off in cold gas efficiency $(51.3 \%)$, while a near $100 \%$ carbon capture with the maximum net efficiency of up to $76.3 \%$ is realisable by integrating CLC and PSA (Case 4) at 25 bar. Integration of oxy-fuel combustion lowered the net efficiency by $2.7 \%$ points due to the need for an air separation unit. In addition, the SESMR with the PSAOG process can be designed as a self-sustaining process without any additional fuel required to meet the process heat utility when the $\mathrm{S} / \mathrm{C}$ ratio is $\sim 3-3.5$.
\end{abstract}




\section{Keywords}

Blue hydrogen production, sorption enhanced steam methane reforming, chemical-looping combustion, carbon capture.

\section{Highlights}

- Six retrofitted sorption enhanced steam methane reforming (SE-SMR) processes are simulated and investigated.

- Sensitivity analysis and competitiveness study are conducted.

- The results offer flexible options for blue $\mathrm{H}_{2}$ production scale up.

- The integration of SE-SMR with pressure swing adsorption and chemical-looping combustion can achieve $\mathrm{CO}_{2}$-free, pure $\mathrm{H}_{2}$ production.

\section{Abbreviations}

$\mathrm{ATR}+\mathrm{GHR}$

AR

ASU

CAL

CCS

FR

MEA

MDEA

PSA

PSAOG

SMR

SE-SMR

TRL
Autothermal Reforming with Gas Heated Reformer

Air reactor

Air separation unit

Calciner

Carbon capture and storage

Fuel reactor

Monoethanolamine

Methyldiethanolamine

Pressure swing adsorption

Pressure swing adsorption

Steam methane reforming

Sorption enhanced steam methane reforming

Technology readiness level 


\section{Introduction}

Hydrogen is widely used in oil refining, ammonia and other chemicals production and also draws significant attention because of its potential to tackle critical decarbonisation related challenges in the transport, and residential sectors, as well as industry and the power sectors. It also has the ability to serve as an energy storage medium for renewables, e.g. solar photovoltaics and wind energy [1]. Current global $\mathrm{H}_{2}$ production is around $75 \mathrm{Mt}$ per annum, of which $76 \%$ is produced from natural gas $\left(205 \mathrm{Gm}^{3}\right.$, or $6 \%$ of current global natural gas use) and $23 \%$ from coal (107 Mt, or 2\% of global coal use), however, its production contributes about $830 \mathrm{Mt} \mathrm{CO}_{2}$ emissions to the atmosphere per year (2\% of global annual emissions) [1]. With the rapid growth rate in $\mathrm{H}_{2}$ demand, $\mathrm{CO}_{2}$ emissions from hydrogen production are predicted to increase significantly, if it is supplied from natural gas or coal without carbon capture and storage (CCS) technologies. These $\mathrm{CO}_{2}$ emissions would limit our ability to use hydrogen as a means of achieving the $2{ }^{\circ} \mathrm{C}$ Paris Agreement goal and mitigating further climate change.

The two conventional ways of producing $\mathrm{H}_{2}$ are Steam Methane Reforming (SMR) and Autothermal Reforming with a Gas Heated Reformer (ATR+GHR), both of which require an additional backend $\mathrm{CO}_{2}$ capture process to decarbonise their processes. To meet climate change targets, it is imperative to develop low-carbon and cost-effective hydrogen production technologies to provide a clean, secure and affordable energy future that can compete with SMR and ATR+GHR coupled with backend $\mathrm{CO}_{2}$ capture. Detailed techno-economic analysis and life cycle assessment of these two technologies with/without $\mathrm{CO}_{2}$ capture are available elsewhere [2].

One innovative option is sorption enhanced steam reforming (SE-SMR), which involves an in-situ $\mathrm{CO}_{2}$ capture process where the hydrocarbon fuel is reacted with steam in the presence of a $\mathrm{CO}_{2}$ sorbent and a reforming catalyst to generate decarbonised, high purity $\mathrm{H}_{2}$ [3]. The concept of SE-SMR is not new. Rostrup-Nielsen [4] reported that the concept of adding a $\mathrm{CO}_{2}$ sorbent to a hydrocarbon-steam-reforming reactor was firstly described in 1868. Williams [5] published a patent for hydrogen production by steam methane reforming in the presence of a mixture of lime and catalyst. Later on, Gorin and Retallick [6] patented a fluidised-bed process by reforming catalyst and $\mathrm{CO}_{2}$ acceptor for hydrogen production. Then, a series of experimental investigation of the different sorbents with Ni catalyst under the multiple SE$\mathrm{SMR} /$ regeneration cycles in a fluidised or packed bed was conducted and described elsewhere [7-11] Recently, Ni-CaO combined sorbent-catalyst materials (CSCM, with $\mathrm{Ni}$ and $\mathrm{CaO}$ on a unique bifunctional kind of particles) have been investigated at industrially relevant conditions and demonstrated satisfactory performance over $100 \mathrm{SE}-\mathrm{SMR} /$ regeneration cycles [12,13]. More insights on the development of SE-SMR technology are available in the review papers by Harrison [14] and Di Giuliano and Gallucci [15]. 
Compared to the conventional processes, high yields of $\mathrm{H}_{2}(\sim 95 \%$, dry basis) can be achieved at relatively low reaction temperatures $\left(650^{\circ} \mathrm{C}\right)$, without the need for multiple shift reactors and significant subsequent purification steps [16]. Although the in-situ $\mathrm{CO}_{2}$ capture process of SE-SMR can remove the majority of the $\mathrm{CO}_{2}$ from the process gas stream, $\mathrm{CO}_{2}$ is still emitted in the process of supplying the heat for the regeneration of the $\mathrm{CO}_{2}$ sorbent and generation of steam. Here too, this $\mathrm{CO}_{2}$ production must be mitigated possibly through a high cost and energy-intensive processes like oxy-fuel combustion or post-combustion capture.

To reduce the cost and maximise the $\mathrm{CO}_{2}$ capture from the SE-SMR technology for hydrogen production, various configurations integrated with SE-SMR have been proposed for low-carbon and high-purity hydrogen production. Ochoa-Fernández et al. [17] conducted a process simulation of the integration of SESMR and oxy-fuel combustion using HYSYS, and the results indicated that SE-SMR with oxy-fuel combustion offers advantages in terms of thermal efficiency, smaller pressure swing adsorption (PSA) unit, and $\mathrm{CO}_{2}$ capture compared to conventional steam reforming with monoethanolamine (MEA) absorption. In addition, with the development of next-generation $\mathrm{CO}_{2}$ capture processes, chemical-looping combustion (CLC) has been proposed for hydrogen production. CLC is a state-of-the-art method for heat and power generation with inherent $\mathrm{CO}_{2}$ separation at low cost and with very low energy penalties compared to oxyfuel combustion [18-21]. CLC is typically carried out in a dual fluidised-bed reactor system, where the oxygen is transported from an air reactor to a fuel reactor by utilising an oxygen carrier (OC) [22]. Rydén et al. [23] first proposed a novel process for the production of $\mathrm{H}_{2}$ by $\mathrm{SMR}$ with inherent $\mathrm{CO}_{2}$ capture by CLC. Subsequently, Ortiz et al. [24] successfully tested the use of an iron-based waste product as an oxygen carrier burning a PSA off-gas in a $500 \mathrm{~W}_{\text {th }}$ unit under continuous operation and demonstrated that it is feasible to apply CLC in steam reforming with the inherent $\mathrm{CO}_{2}$ separation. Recently, many studies [2527] have carried out process simulations and thermodynamic analyses for the integration of CLC with SESMR and have shown some very promising results in terms of energy efficiency, $\mathrm{H}_{2}$ purity and overall $\mathrm{CO}_{2}$ capture efficiency. Besides indirect integration of CLC with SE-SMR, other novel concepts for Ca-Cu looping and sorption enhanced-chemical looping methane reforming for hydrogen production have also been intensively investigated [28-31]. The most recent achievements for the development of Ca-Cu looping technology were reviewed by Martínez et al. [32].

Although the concept of low-carbon hydrogen production by SE-SMR thermally coupling CLC has been simulated, the hydrogen product purity (92-98\%) from previous CLC-SE-SMR investigation is still too low for some end-use applications such as fuel cells, electronics and polysilicon production. Thus, a hydrogen purification unit such as PSA or membrane separation must be installed to enhance the hydrogen purity, and the off-gas from the hydrogen purification unit can be recycled to the fuel reactor, which will reduce 
the additional fuel supply and improve the overall $\mathrm{CO}_{2}$ capture. Also, these previous works have used a simplified modelling approach to model the heat network of SE-SMR with CLC process, which potentially results in less accurate values of process efficiency.

Moreover, past studies [25-27] evaluated the process simulation of the SE-SMR with CLC based on NiO/Ni oxygen carriers. Unfortunately, nickel oxides are among the most expensive oxygen carriers and have health, safety and environmental risks, as well as thermodynamic restrictions for fuel conversion, which mean that they are unlikely to be deployed in commercial CLC systems [33-35]. Therefore, low cost and less hazardous oxygen carriers such as iron-based oxygen carries must be investigated for this process.

The purpose of this work is to evaluate the potential performance and to provide a comprehensive investigation of six new process configurations of SE-SMR integrated with pressure swing adsorption, an iron-based CLC, and oxyfuel combustion for low-carbon and high-purity hydrogen production. In this work, six different SE-SMR process models with a detailed heat exchanger network design are employed to understand the thermodynamic limitations of achieving the maximum cold gas efficiency and net efficiency whilst simultaneously capturing the greatest quantity of $\mathrm{CO}_{2}$ from the production process. Sensitivity studies have also been performed for all six cases to better understand the influence of reformer pressure, temperature and steam to carbon molar ratio $(\mathrm{S} / \mathrm{C})$ on the $\mathrm{CH}_{4}$ conversion, $\mathrm{CO}_{2}$ capture efficiency, $\mathrm{H}_{2}$ purity, cold gas efficiency and net efficiency. 


\section{Process configuration and modelling}

\subsection{Process configuration}

$\mathrm{H}_{2}$ production by SE-SMR with a PSA unit, and integrated with CLC or an oxy-fired or a $\mathrm{H}_{2}$-fired calciner has been proposed and simulated in Aspen Plus. The performance of the different cases has been evaluated on the basis of $\mathrm{CH}_{4}$ conversion, $\mathrm{H}_{2}$ purity, $\mathrm{CO}_{2}$ capture efficiency, cold gas efficiency and net efficiency. Figure 1 shows the simplified flow diagrams of the six simulated cases. Detailed flowsheets for each case can be found in Supplementary materials.

(a) Case 1: SESMR

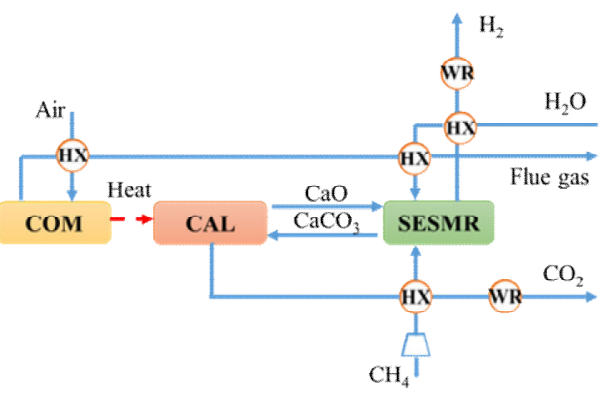

(c) Case 3: SESMR + CLC

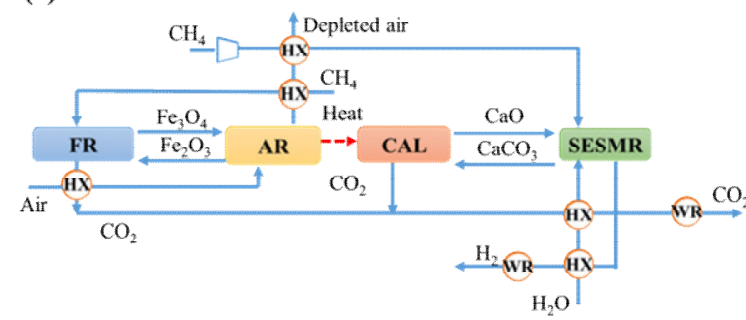

(e) Case 5: SESMR + PSA + Oxy-fuel combustion

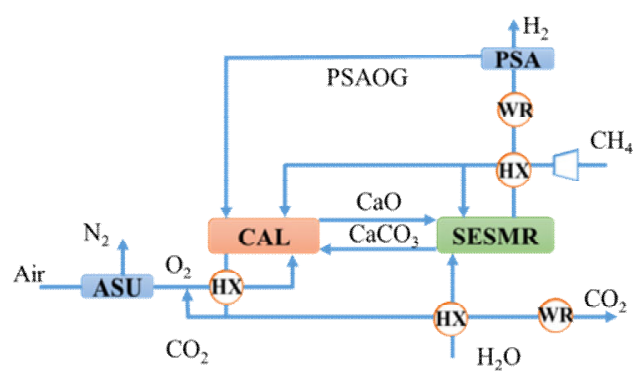

(b) Case 2: SESMR + PSA

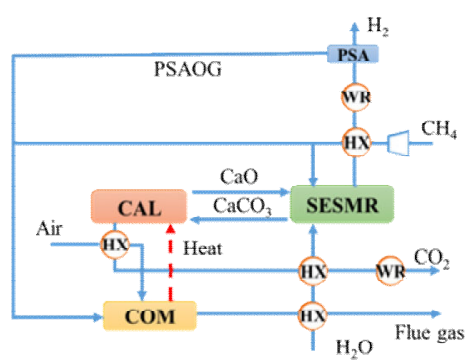

(d) Case 4: SESMR + PSA + CLC

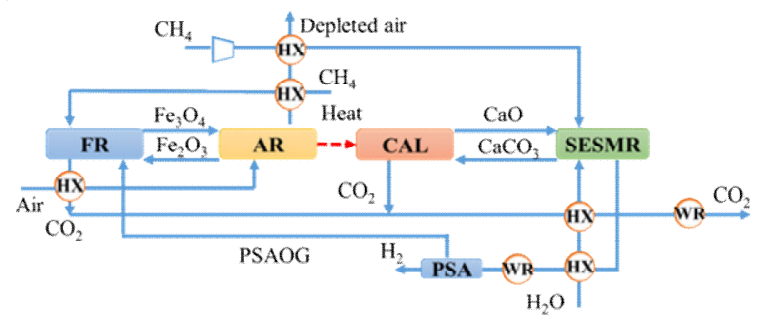

(f) Case 6: SESMR + PSA $+\mathrm{H}_{2}$ Recycle

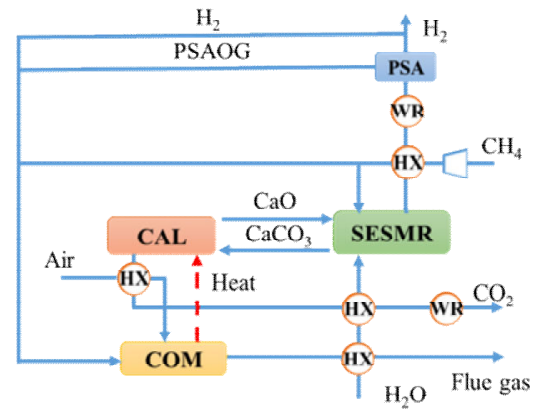

Figure 1 Flow diagrams of different simulated sorption enhanced steam methane reforming processes with $\mathrm{CO}_{2}$ capture. CAL: sorbent regenerator (calciner), COM: combustor SE-SMR: sorption enhanced steam methane reformer, HX: heat exchanger, WR: water removal, PSA: pressure swing absorption unit,

FR: fuel reactor, AR: air reactor, ASU: air separation unit. 


\subsubsection{Case 1: SE-SMR system}

In the SE-SMR process, the compressed feed $\mathrm{CH}_{4}$ is preheated by the heat from the $\mathrm{CO}_{2}$ enriched gas from sorbent regenerator, and then mixed with $\mathrm{CaO}$ sorbent before entering the reformer with the hightemperature steam. Steam is produced from the waste heat of the reforming gas products and flue gas from an air-fired burner used for sorbent regeneration. The reformer in the SE-SMR process is a joint carbonator and reformer, which can achieve in-situ $\mathrm{CO}_{2}$ separation in the presence of $\mathrm{CaO}$ or other $\mathrm{CO}_{2}$ sorbents. The capture of $\mathrm{CO}_{2}$ shifts the reforming and water-gas shift reactions in favour of more $\mathrm{H}_{2}$ production according to Le Chatelier's principle. The produced $\mathrm{CaCO}_{3}$ solids (if a CaO-based sorbents are used) are separated from gas stream and regenerated by an indirect air-fired methane calciner for a closed-loop operation. The gas product is further cooled via a cooler and water is condensed by a condenser, allowing an enriched $\mathrm{H}_{2}$ product to be obtained. The overall SE-SMR reaction can be simplified to Eq.(1).

$$
\mathrm{CH}_{4}+2 \mathrm{H}_{2} \mathrm{O}+\mathrm{CaO} \leftrightarrow \mathrm{CaCO}_{3}+4 \mathrm{H}_{2}
$$

The operating pressure of the reformer was set between 5 and 25 bar, which can be maintained by the feed pressure and adjusted by the back pressure controller of the reformer. There are two pressurising lock hoppers installed in the inlet and outlet of the calciner respectively, which can ensure the regeneration of $\mathrm{CaO}$ at atmospheric pressure.

\subsubsection{Case 2: SE-SMR + PSA}

In this case, the cooled and condensed $\mathrm{H}_{2}$-enriched gas from the SE-SMR process is sent to the PSA unit at a feed pressure of 25 bar. A near pure $\mathrm{H}_{2}$ stream is then produced from the separated product gas. The offgas stream containing $\mathrm{CH}_{4}, \mathrm{CO}, \mathrm{CO}_{2}, \mathrm{H}_{2}$ and $\mathrm{H}_{2} \mathrm{O}$ is sent to the air-fired burner to reduce the additional fuel requirement.

\subsubsection{Case 3 and 4: SE-SMR + CLC without/with PSA}

To avoid the release of $\mathrm{CO}_{2}$ emissions from the calcination of $\mathrm{CaCO}_{3}, \mathrm{CLC}$ has been integrated with the SE-SMR process (See Figure 1 (c) and (d)). In previous work on process simulation of SE-SMR + CLC, only Ni-based oxygen carriers, which have a thermodynamic restriction in that they cannot convert fuels fully to $\mathrm{CO}_{2}$ and $\mathrm{H}_{2} \mathrm{O}$, have been selected. Although the Ni-based oxygen carriers have a higher reactivity for $\mathrm{CH}_{4}$, it is also among the most expensive of such materials and also has health, safety and environmental issues. In this work, a $\mathrm{Fe}_{2} \mathrm{O}_{3} / \mathrm{Fe}_{3} \mathrm{O}_{4}$ oxygen carrier supported by $\mathrm{Al}_{2} \mathrm{O}_{3}\left(15\right.$ wt \%) and $\mathrm{SiO}_{2}(15 \mathrm{wt} \%)$ has been chosen for the CLC process. Such iron based oxygen carriers have been successfully operated in different CLC pilot plants with coal, biomass, $\mathrm{CH}_{4}$ and PSA off-gas [24,36-38]. A nickel-based CLC-SESMR process, is also investigated for the purpose of comparison. 
The CLC unit is used to supply heat to the SE-SMR process. In Case 3, $\mathrm{Fe}_{2} \mathrm{O}_{3}$ reacts with the $\mathrm{CH}_{4}$ in the fuel reactor (FR), and the reduced oxygen carrier $-\mathrm{Fe}_{3} \mathrm{O}_{4}$ is circulated to the air reactor (AR) and reoxidised. The reduction of $\mathrm{Fe}_{2} \mathrm{O}_{3}$ by $\mathrm{CH}_{4}$ is endothermic (Eq.(2)), and the oxidation of $\mathrm{Fe}_{3} \mathrm{O}_{4}$ is an exothermic process (Eq.(3)). The released heat from the AR is utilised to provide the necessary heat for the calciner via a fluidised-bed heat exchanger [39] or heat pipes [40,41] as shown in Figure 2. Junk et al. [41] have conducted a technical and economical assessment of the indirectly heated carbonate looping by heat pipes, which indicates that the $\mathrm{CO}_{2}$ avoidance costs of the indirectly heated carbonate looping by heat pipes is about $€ 22.6 / \mathrm{CO}_{2}$. This is much lower than that of oxy-fuel combustion or standard carbonate looping ( $€ 36$ and $€ 26 / \mathrm{tCO}_{2}$ ). It is assumed $10 \%$ heat loss occurs during the heat transfer from the AR to the calciner, which is based on the recent testing of an indirectly heated calciner at a $300 \mathrm{kWth}$ scale in Darmstadt $[42,43]$. The oxygen carriers and inert materials also carry the required amount of heat for $\mathrm{CH}_{4}$ reduction in the FR as it is operated under adiabatic conditions. The heat from the depleted air from the AR and flue gas from the FR is used to preheat the $\mathrm{CH}_{4}$ feed gas and to produce steam to the reformer. In Case 4, the PSA unit is installed after the reformer to generate high-purity $\mathrm{H}_{2}$ and the PSA off-gas (PSAOG) is combined with $\mathrm{CH}_{4}$, which is combusted in the FR as shown by Eq.(2), Eq.(4) and Eq.(5).

$$
\begin{array}{ll}
\mathrm{CH}_{4}+12 \mathrm{Fe}_{2} \mathrm{O}_{3} \rightarrow \mathrm{CO}_{2}+2 \mathrm{H}_{2} \mathrm{O}+8 \mathrm{Fe}_{3} \mathrm{O}_{4} & \text { Equation (2) } \\
\mathrm{O}_{2}+4 \mathrm{Fe}_{3} \mathrm{O}_{4} \rightarrow 6 \mathrm{Fe}_{2} \mathrm{O}_{3} & \text { Equation (3) } \\
\mathrm{H}_{2}+3 \mathrm{Fe}_{2} \mathrm{O}_{3} \rightarrow \mathrm{H}_{2} \mathrm{O}+2 \mathrm{Fe}_{3} \mathrm{O}_{4} & \text { Equation (4) } \\
\mathrm{CO}+3 \mathrm{Fe}_{2} \mathrm{O}_{3} \rightarrow \mathrm{CO}_{2}+2 \mathrm{Fe}_{3} \mathrm{O}_{4} & \text { Equation (5) }
\end{array}
$$




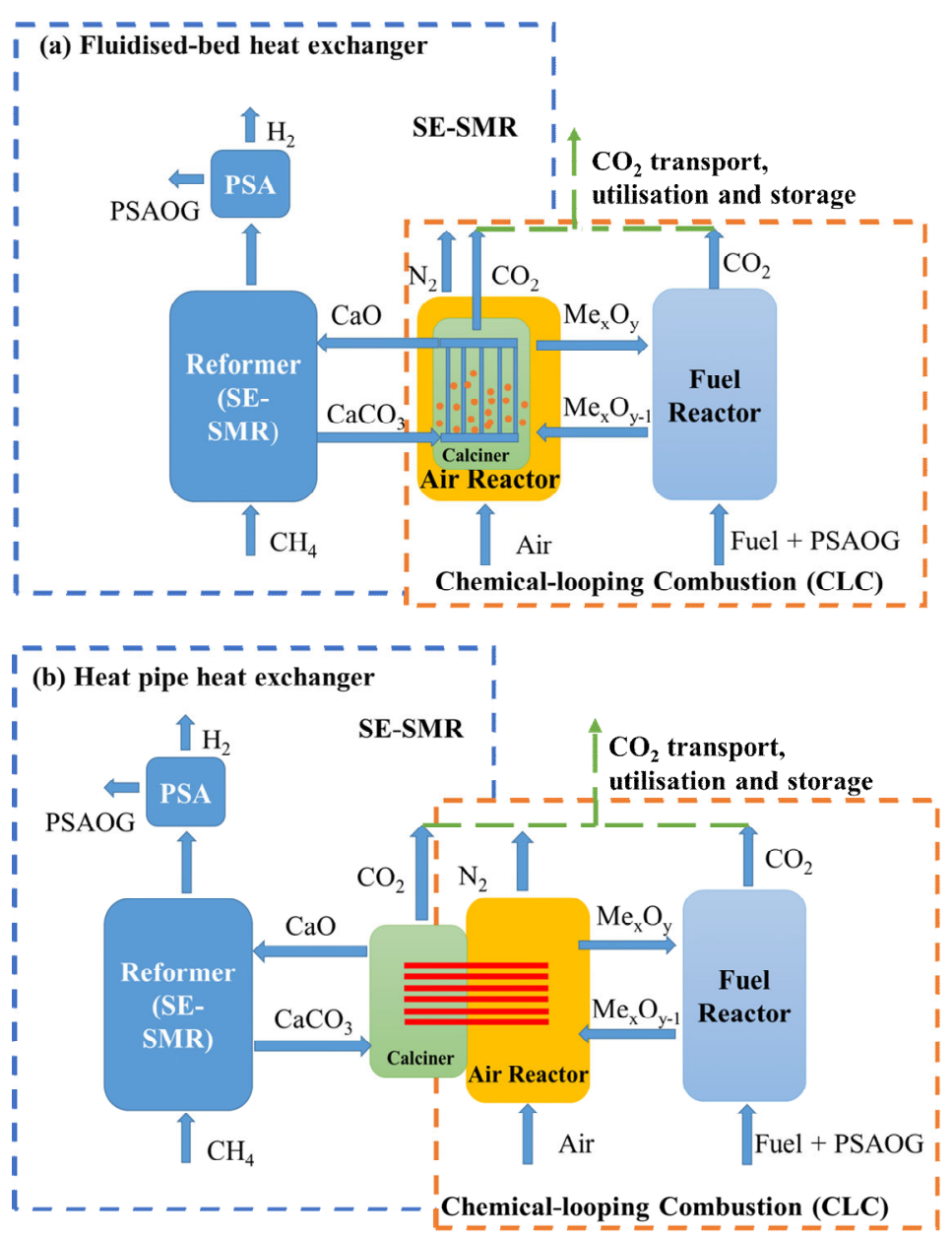

Figure 2 Options of heat integration between the air reactor and calciner

\subsubsection{Case 5 and 6: $\mathrm{SE}-\mathrm{SMR}+\mathrm{PSA}+\mathrm{Oxy}$-fuel combustion and $\mathrm{H}_{2}$ recycle}

Due to the highly endothermic process of the $\mathrm{CaO}$ sorbents regeneration, i.e. calcination of $\mathrm{CaCO}_{3}$, a large amount of heat is required by the calciner. To obtain high-purity $\mathrm{CO}_{2}$ from the calciner, direct oxy-fuel combustion is used for the calcium-looping process, which has been demonstrated at the pilot-plant scale [44,45]. In Case 5, $\mathrm{CH}_{4}$ along with the PSAOG is introduced into the calciner and burnt in an $\mathrm{O}_{2} / \mathrm{CO}_{2}$ environment. Oxygen is produced in an Air Separation Unit (ASU) and the recirculated flue gas from the calciner is used to avoid superheated regions in the calciner, which operate at $900{ }^{\circ} \mathrm{C}$. The high-temperature $\mathrm{CO}_{2}$ rich gas stream leaving the calciner is utilised to preheat the fuel and steam. In Case 6, a new process integration of a $\mathrm{H}_{2}$-fired calciner with SE-SMR is proposed to avoid the energy penalty and capital cost of the ASU. The heat from the burning of $\mathrm{H}_{2}$ and PSAOG is transferred through the metallic walls or heat pipes or the hot solids circulating between the combustor and the calciner. The extracted heat from the flue gas of the $\mathrm{H}_{2}$ combustor is used to preheat the steam to the reformer and the air to the combustor. 


\subsection{Process modelling}

The SE-SMR process was modelled in Aspen Plus under steady-state equilibrium conditions. The chemical equilibrium of the reformer and calciner were modelled using the RGibbs block, which minimises the Gibbs free energy of all the species. The Gibbs free energy minimisation method is based on the idea that the investigated chemical system is thermodynamically feasible when total Gibbs free energy has the lowest value and differential of Gibbs free energy is zero for current operation conditions [46,47]. Since the reformer is slightly endothermic (balanced by the exothermic carbonation reaction), the heat duty of this reactor is set to zero, therefore, the additional heat duty is nil (adiabatic). Consequently, the reformer outlet temperature is lower than the inlet. The reformer temperature reported in this paper refers to the reformer outlet temperature unless otherwise specified. Table 1 shows all the thermodynamic modelling assumptions of the base model.

The heat exchanger networks are designed in-order to ensure the maximum possible heat recovery, with minimum number of heat exchangers. The steam generator is modelled with multiple zones to detect/avoid temperature crossover during phase-change. The fuel feed to the reformer is adjusted to ensure the volume flow rate of $\mathrm{H}_{2}$ product is $1500 \mathrm{~kg} / \mathrm{h}$, equivalent to $50 \mathrm{MW}$ th based on the lower heating value of hydrogen, for all cases. In addition, design specifications are also defined to ensure the S/C ratio is set to the desired values. The air mass flow to the air- $\mathrm{CH}_{4}$ combustor is adjusted to ensure the excess $\mathrm{O}_{2}$ in the flue gas stream is maintained at $5 \%$ molar basis. The flue-gas is cooled to a minimum value of $50{ }^{\circ} \mathrm{C}$ (wherever possible) to estimate the maximum possible cold gas efficiency of the system. The carbonation efficiency of the $\mathrm{CaO}$ sorbent is enhanced under SE-SMR conditions (in the presence of steam and at elevated pressure), and acceptable mechanical stability of the sorbent can be achieved if the catalytic and sorbent particles are supported into combined sorbent-catalyst materials $[12,48]$. Based on recent long term cycling experimental results, it is estimated the average carbonation conversion of $\mathrm{CaO}$ sorbent during the SE-SMR process should be around $50 \%$ [12,16], this value dictates the ratio of $\mathrm{Ca} / \mathrm{C}$ in the reformer and can be maintained by ensuring an effective make-up flow of the sorbent/combined particles. The pressures reported in this work are expressed as absolute pressure. 
Table 1 Design assumptions used for developing the process flowsheet models in Aspen Plus

\begin{tabular}{|c|c|c|}
\hline Parameters & Value & Unit \\
\hline Reformer pressure & 25 & bar \\
\hline Reformer temperature & 600 & ${ }^{\circ} \mathrm{C}$ \\
\hline Reformer S/C & 5 & - \\
\hline Calciner temperature & 900 & ${ }^{\circ} \mathrm{C}$ \\
\hline $\mathrm{CH}_{4}$ compressor efficiency & 83 & $\%$ \\
\hline $\mathrm{H}_{2}$ compressor efficiency & 83 & $\%$ \\
\hline Water pump efficiency & 83 & $\%$ \\
\hline Excess oxygen & 5 & $\%$ \\
\hline Heat exchanger pinch & 20 & ${ }^{\circ} \mathrm{C}$ \\
\hline Calciner heat loss & 10 & $\%$ \\
\hline Calcination efficiency & 100 & $\%$ \\
\hline Mechanical efficiency of pump and compressors & 98 & $\%$ \\
\hline Fuel feed temperature & 9 & ${ }^{\circ} \mathrm{C}$ \\
\hline Fuel feed pressure & 1 & bar \\
\hline Feed water inlet temperature & 20 & ${ }^{\circ} \mathrm{C}$ \\
\hline Feed water inlet pressure & 1 & bar \\
\hline Air/oxygen temperature & 25 & ${ }^{\circ} \mathrm{C}$ \\
\hline Air/oxygen pressure & 1 & bar \\
\hline
\end{tabular}

The $\mathrm{H}_{2}$ purity of the conventional SE-SMR can be enhanced by adding a PSA unit downstream of the reformer. The off-gas from the PSA (PSAOG) contains $\mathrm{H}_{2}, \mathrm{CO}$, and $\mathrm{CH}_{4}$ and is burned to partly meet the calciner heat duty. The carbon capture for the process can also be enhanced owing to the reduced fuel consumption needed to meet the heat utilities for the cycle. The PSAOG along with additional fuel (methane) is burned in air to meet the cycle utility requirement. A 95\% separation efficiency for the PSA 
is considered reasonable. In addition, the inlet pressure to the PSA is always maintained higher than 25 bar, which is the typical operating pressure for PSA. When simulating the sensitivity study for different reformer pressures, an additional compressor is placed upstream of the PSA to match the pressure. The isentropic efficiency of the compressor is assumed to be $83 \%$ with a mechanical efficiency of $98 \%$. The additional fuel is tuned to match the process heat utility requirement.

The SE-SMR model is integrated with CLC in Aspen Plus as shown in Figure 1 (c) and (d). Both the fuel and air reactors are modelled using the RGibbs reactor. The Air Reactor (AR) supplies the calciner heat duty and the flue gas from the Fuel Reactor (FR) and AR are used to generate steam and preheat the fuel and air. Both FR and AR operate at ambient pressure. The air flow to the AR is controlled to meet 5\% excess oxygen requirement at the AR outlet flue gas stream. The mass flow of the oxygen carrier is adjusted until all the hydrogen is completely burned in the FR outlet flue gas stream, and the heat load connected to them dictates the temperatures. The AR outlet temperature varies as the calciner heat-duty changes since the AR is directly coupled with the calciner and the outlet temperature of the AR flue gas is maintained higher than the calciner operating temperature (i.e. $900{ }^{\circ} \mathrm{C}$ ). The fuel reactor is set as an adiabatic reactor (i.e. heat duty $=0$ ), consequently, the FR temperature is dictated by the fuel and oxygen carrier inlet conditions. Additional methane is supplied as a fuel to the FR for this case. Since many different oxygen carriers are possible only two of the most common oxygen carriers are modelled here. $\mathrm{Fe}_{2} \mathrm{O}_{3}$ is used in all the sensitivity studies and $\mathrm{NiO}$ is modelled separately to compare the performance difference to the ironbased oxygen carrier.

In Case 4, a PSA was added to the SE-SMR+CLC configuration and the PSAOG is connected to the FR to reduce the additional fuel requirement. In Case 5, SE-SMR+PSAOG configuration is integrated with oxycombustion system to meet the heat duty of the calciner and steam generation. The $160 \mathrm{kWh} / \mathrm{t}$ of oxygen is assumed as the auxiliary power consumption of the air separator [49]. Here, $30 \%$ oxygen and $70 \%$ of $\mathrm{CO}_{2}$ mole fraction gas is supplied to the oxy-fuel combustor. In Case 6, the SE-SMR is scaled-up in such a way that part of the product hydrogen together with the PSAOG can meet the heat utility requirement of the process. Therefore, no additional fuel is added to meet the heat utility requirement.

\subsection{Performance evaluation}

The thermal performance of the six different cases were compared based on the five performance indexes: 1) $\mathrm{CH}_{4}$ conversion 2) $\mathrm{H}_{2}$ purity 3) cold gas efficiency 4) net efficiency 5) $\mathrm{CO}_{2}$ capture efficiency. The methane conversion is calculated according to Eq.(6) where $n_{C H 4, \text { in }}$ and $n_{C H 4, \text { out }}$ are the moles of methane flow at the inlet and outlet of the reformer respectively. The hydrogen purity was defined as the hydrogen mole fraction of the product stream from the plant, on a dry basis. 


$$
\operatorname{conv}_{\mathrm{CH}_{4}}=\left(1-\frac{\mathrm{n}_{\mathrm{CH}_{4}, \text { out }}}{\mathrm{n}_{\mathrm{CH}_{4}, \text { in }}}\right) * 100
$$

The cold gas efficiency $\left(\eta_{C G}\right)$ was calculated using Eq.(7) where $\dot{m}_{H_{2}, \text { product }}, \dot{m}_{C H_{4}, \text { feed }}, \dot{m}_{C H_{4}, \text { external }}$ are the mass flow rates of the product hydrogen, feed methane and additional methane required to meet the heat utility of the calciner and steam boiler, respectively. $L H_{H_{2}}, L H V_{C_{4}}$ are the lower heating value of hydrogen $(120 \mathrm{MJ} / \mathrm{kg})$ and methane $(50 \mathrm{MJ} / \mathrm{kg})$, respectively.

$$
\eta_{\mathrm{CG}}=\left(\frac{\dot{\mathrm{m}}_{\mathrm{H}_{2}, \text { product }} * \mathrm{LHV}_{\mathrm{H}_{2}}}{\left(\dot{\mathrm{m}}_{\mathrm{CH}_{4}, \text { feed }}+\dot{\mathrm{m}}_{\mathrm{CH}_{4}, \text { additional }}\right) * \mathrm{LHV}_{\mathrm{CH}_{4}}}\right) * 100
$$

The net efficiency $\left(\eta_{\text {net }}\right)$ is calculated using Eq. (8) where the electric utility $\left(P_{e}\right)$ requirement is also added to the cold gas efficiency equation. A thermal to electric conversion efficiency $\left(\eta_{\text {elect }}\right)$ of $50 \%$ is utilised in this work.

$$
\eta_{\text {net }}=\left(\frac{\dot{\mathrm{m}}_{\mathrm{H}_{2} \text {,product }} * \mathrm{LHV}_{\mathrm{H}_{2}}}{\left(\dot{\mathrm{m}}_{\mathrm{CH}_{4}, \text { feed }}+\dot{\mathrm{m}}_{\mathrm{CH}_{4} \text {,additional }}\right) * \mathrm{LHV}_{\mathrm{CH}_{4}}+\frac{\mathrm{P}_{\mathrm{e}}}{\eta_{\text {elect }}}}\right) * 100
$$

The overall $\mathrm{CO}_{2}$ capture efficiency is calculated using Eq.(9) where $n_{\mathrm{CO}_{2} \text {,captured }}$ is the moles of carbon capture.

$$
\mathrm{CO}_{2} \text { capture efficiency }=\left(\frac{\mathrm{n}_{\mathrm{CO}_{2} \text {, captured }}}{\mathrm{n}_{\mathrm{CH}_{4}, \text { feed }}+\mathrm{n}_{\mathrm{CH}_{4} \text {, additional }}}\right) * 100
$$

Equation (9)

\section{Results and discussion}

\subsection{Thermodynamics analysis}

In this section, a sensitivity analysis including the effects of reforming temperature, reforming pressure and $\mathrm{S} / \mathrm{C}$ ratio (molar ratio of steam to carbon) on the performance of the above cases was conducted to investigate the optimal operating conditions and process configurations for the low-carbon and high-purity hydrogen production.

\subsubsection{Effect of reforming temperature}

The effect of the reformer temperature on the six different cases are plotted in Figure 3. Since the reformer is slightly endothermic, increasing the temperature also favours the forward reaction following Le Chatelier's principle. In the base case (Case 1), the methane conversion changes linearly from $83.7 \%$ at 500 ${ }^{\circ} \mathrm{C}$ to $87.1 \%$ at $700{ }^{\circ} \mathrm{C}$. In addition, the hydrogen purity also increases slightly from $95.3 \%$ to $95.9 \%$ until $650{ }^{\circ} \mathrm{C}$ and then begins to drop at $700{ }^{\circ} \mathrm{C}$ by $0.1 \%$ points. Since the methane conversion increases with the 
reformer temperature, the fuel feed reduces linearly in order to achieve a $50 \mathrm{MWth}$ plant output, reducing the fuel compressor power. This also implies that the steam flow rate reduces linearly in order to maintain the desired S/C ratio in the reformer inlet, lowering the pump power requirement. The reduction of the feed flow rate is roughly compensated by the increase in the methane conversion at a higher reformer temperature, consequently the sorbent flow rate reduces by about only $0.5 \%$ when the reformer temperature increases from $500{ }^{\circ} \mathrm{C}$ to $650{ }^{\circ} \mathrm{C}$. At $700{ }^{\circ} \mathrm{C}$, the sorbent flow rate reduced by $1.5 \%$ in order to minimise the reformer Gibbs free energy. Furthermore, the calciner heat duty declines owing to the narrow temperature window at a higher reformer temperature. The additional methane required to meet the process heat utility is also reduced by about $1.6 \%$ at $700{ }^{\circ} \mathrm{C}$ reformer temperature owing to the reduced heat utility. The overall $\mathrm{CO}_{2}$ capture efficiency is driven by the efficiency of the in-situ reformer carbon capture and the carbon capture of the additional fuel firing. The latter is not captured in Case 1, therefore, the overall $\mathrm{CO}_{2}$ capture efficiency is expected to increase with the increase in the reformer temperature owing to the reduction in the fuel inlet flow rate. However, the in-situ $\mathrm{CO}_{2}$ capture efficiency of the reformer reduces significantly after $650{ }^{\circ} \mathrm{C}$. Finally, the $\mathrm{CO}_{2}$ capture efficiency increases from $57.6 \%$ to $58.6 \%$ when the reformer temperature increases from $500{ }^{\circ} \mathrm{C}$ to $650{ }^{\circ} \mathrm{C}$ and decreases to $58.1 \%$ at $700{ }^{\circ} \mathrm{C}$ owing to the reduction in the carbonation efficiency. The cold gas efficiency linearly increases with the reformer temperature owing to the increase of methane conversion, which subsequently reduces the feed flow, steam flow, the calciner heat duty. In addition, the net efficiency also linearly increased with the reformer temperature with the negative offset from the cold gas efficiency due to the natural gas compressor and water pump power consumption (1.6\% points). 

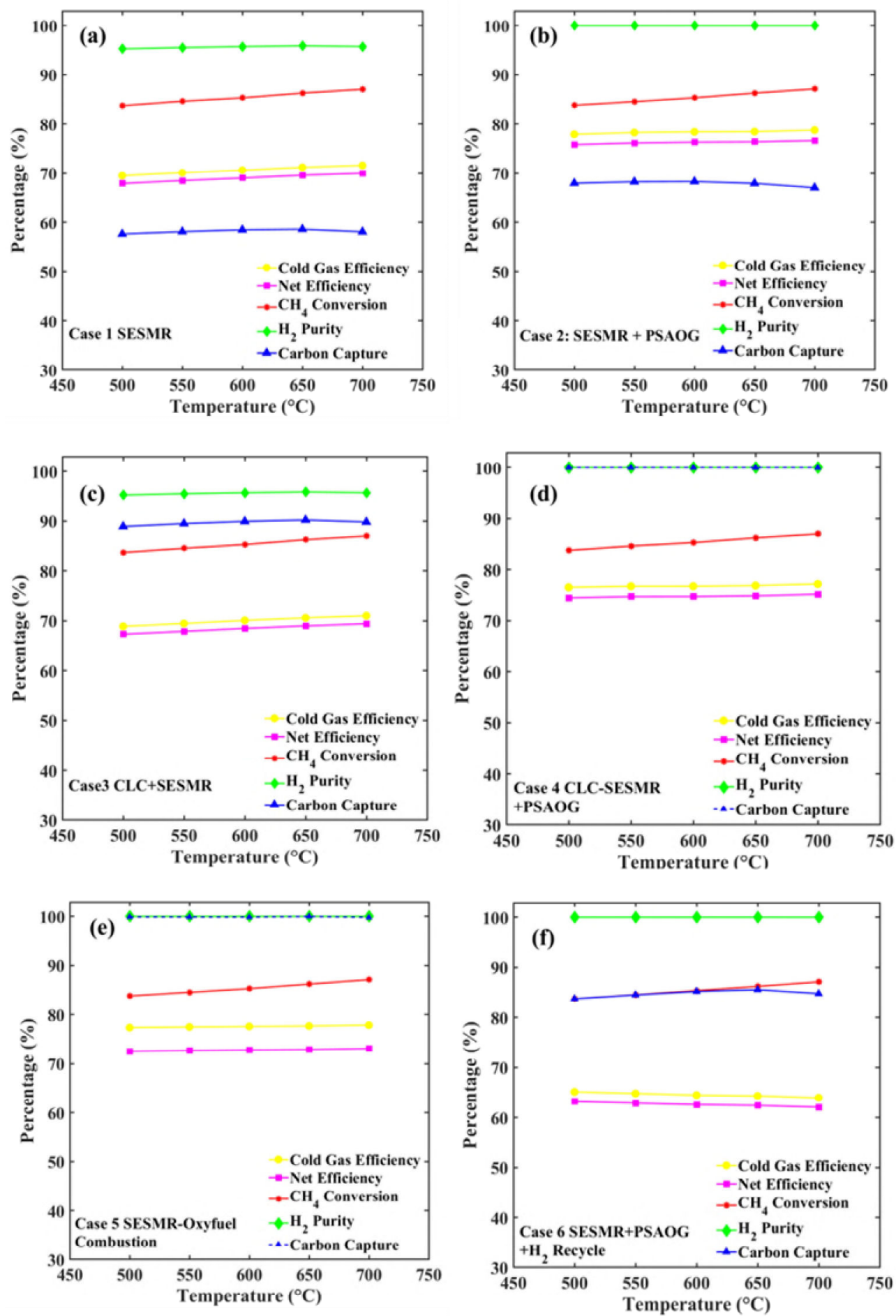

Figure 3 Process performance for different reforming temperatures. (a) Case 1 SE-SMR, (b) Case 2 SESMR+PSAOG, (c) Case 3 CLC+SE-SMR, (d) Case 4 CLC+SE-SMR+PSAOG, (e) Case 5 SE-

$\mathrm{SMR}+\mathrm{Oxy}$-fuel combustion, (f) Case $6 \mathrm{SE}-\mathrm{SMR}+\mathrm{H}_{2}$ recycle 
Adding a PSA (Case 2) increases the hydrogen purity close to $100 \%$ and utilising the PSAOG to provide the process heat improves the efficiency and the amount of $\mathrm{CO}_{2}$ captured. The methane conversion in Case 2 follows the same trend as Case 1 since the reformer boundary conditions are unaffected. The heating value of the PSAOG depends on the methane conversion of the reformer. The in-situ carbon capture efficiency of the reformer follows a similar trend as Case 1, i.e. the $\mathrm{CO}_{2}$ capture efficiency declines after $650{ }^{\circ} \mathrm{C}$, with the positive offset of $9 \%$ points at $700{ }^{\circ} \mathrm{C}$ and $10.3 \%$ points at $500{ }^{\circ} \mathrm{C}$. In addition, the cold gas efficiency is increased by $0.8 \%$ points due to the increase in PSAOG heating value as the methane conversion increases by $3.3 \%$ points. The difference between the cold gas efficiency and net efficiency is $2.1 \%$ points for all temperatures.

In Case 3, a CLC process is added in the additional fuel firing circuit but does not include a PSA in the overall plant layout. Therefore, the trend of methane conversion and hydrogen purity are the same as in Case 1 as the boundary conditions to the reformer are unaffected. The $\mathrm{CO}_{2}$ capture efficiency is higher than both Case 1 and 2 as the $\mathrm{CO}_{2}$ evolved from firing the additional fuel is also captured. The $\mathrm{CO}_{2}$ capture efficiency trend is similar to Case 1 with a positive offset and it reached the maximum value of $90.2 \%$ at $650{ }^{\circ} \mathrm{C}$ and declined to $89.8 \%$ at $700{ }^{\circ} \mathrm{C}$. Although the cold gas efficiency trend is similar to Case 1 , the absolute values were lower by $0.6 \%$ points for all the temperatures. This is due to the inefficiency in handling the heat from both fuel and air reactors as the heat network was optimised to extract heat from single flue gas stream from the combustor. Advanced heat exchanger network design could bridge this gap with additional capital cost. The same is also true for the net efficiency trend, which was negatively offset by $1 \%$ points for all the temperatures.

The performance trend of Case 4 is shown in Figure 3 (d) and it can be observed that the methane conversion is the same as Case 1 whilst the hydrogen purity is near $100 \%$ for all the temperatures due to the presence of PSA. The $\mathrm{CO}_{2}$ capture efficiency is also close to $100 \%$ for all temperatures owing to the combination of PSAOG and CLC. The cold gas efficiency and the net efficiency trends are similar to Case 2 with the negative offset of $1.5 \%$ points. For the oxy-combustion with PSAOG scenario (Case 5), the carbon conversion is similar to Case 1 and the hydrogen purity reaches near $100 \%$ for all temperature. The carbon capture efficiency also reaches nearly 100\% as shown in Figure 3(e). The cold gas efficiency is about the same as Case 2 whereas the net efficiency is lower by about $3.3 \%$ due to the auxiliary power consumption of air separation unit.

In Case 6, the methane conversion is similar to Case 2 and the hydrogen purity reaches $\sim 100 \%$. The $\mathrm{CO}_{2}$ capture efficiency trend is similar to Case 2 with the positive offset. The increase in the $\mathrm{CO}_{2}$ capture efficiency is due to the use of additional carbon free fuel (product hydrogen) to meet the heat requirement. 
However, the maximum carbon capture is $85.6 \%$ at a $650{ }^{\circ} \mathrm{C}$ reformer temperature. A further increase of reformer temperature to $700{ }^{\circ} \mathrm{C}$ reduced the $\mathrm{CO}_{2}$ capture efficiency by $0.8 \%$ points. The $\mathrm{CO}_{2}$ capture efficiency is limited by the methane conversion ratio and the in-situ carbon capture efficiency in the reformer. However, this increase in $\mathrm{CO}_{2}$ capture efficiency comes at the expense of the process cold gas efficiency. Since the heat content of the product hydrogen from an SE-SMR is lower than the heat content of the feed methane by the factor related to its cold gas efficiency, switching the additional fuel (methane) to product hydrogen is associated with penalties in terms of the process efficiency of the same magnitude. The cold gas efficiency of Case 6 is lower than Case 2 by $12.7 \%$ at $500{ }^{\circ} \mathrm{C}$ and $14.8 \%$ at $700{ }^{\circ} \mathrm{C}$. The fuel feed increases by $0.4 \%$ with the reformer temperature in order to maintain the fixed $\mathrm{H}_{2}$ output, which is opposite to Case 2. Nevertheless, the calciner heat duty declines owing to the reduced temperature window at higher reformer temperatures.

\subsubsection{Effect of reforming pressure}

The sensitivity of reformer pressure was investigated for all six cases and the results are presented in Figure 4. For Case 1, the methane conversion declines with a pressure increase according to Le Chatelier's principle. This affects the hydrogen purity, which reduces by $2.7 \%$ points with a pressure increase from 5 bar to 25 bar. The maximum hydrogen purity is $98.4 \%$ at 5 bar. The fuel feed increases with the reformer pressure by $11.5 \%$ from 5 bar to 25 bar to maintain the plant capacity at 50 MWth with the lower methane conversion. This also increases the steam flow by the same order to maintain the S/C ratio constant. Since the methane conversion is lower at higher pressure the methane mole fraction in the product stream increases from $1.2 \%$ to $4.1 \%$ when the reformer pressure increases from 5 bar to 25 bar. This together with the effect of increasing fuel inlet flow rate to meet the increased heat requirement reduces the $\mathrm{CO}_{2}$ capture efficiency at higher pressures. Although the specific energy required to heat the water from $9{ }^{\circ} \mathrm{C}$ to $600{ }^{\circ} \mathrm{C}$ reduces at a higher pressure owing to the reduced latent heat, the increased steam flow rate dominates, thus increased the heat requirement. The cold gas efficiency decreases at higher pressure owing to the higher additional fuel requirement. The difference between cold gas efficiency and net efficiency increases from $0.8 \%$ points at 5 bar to $1.6 \%$ points at 25 bar, owing to the increase electrical power at higher pressures. 

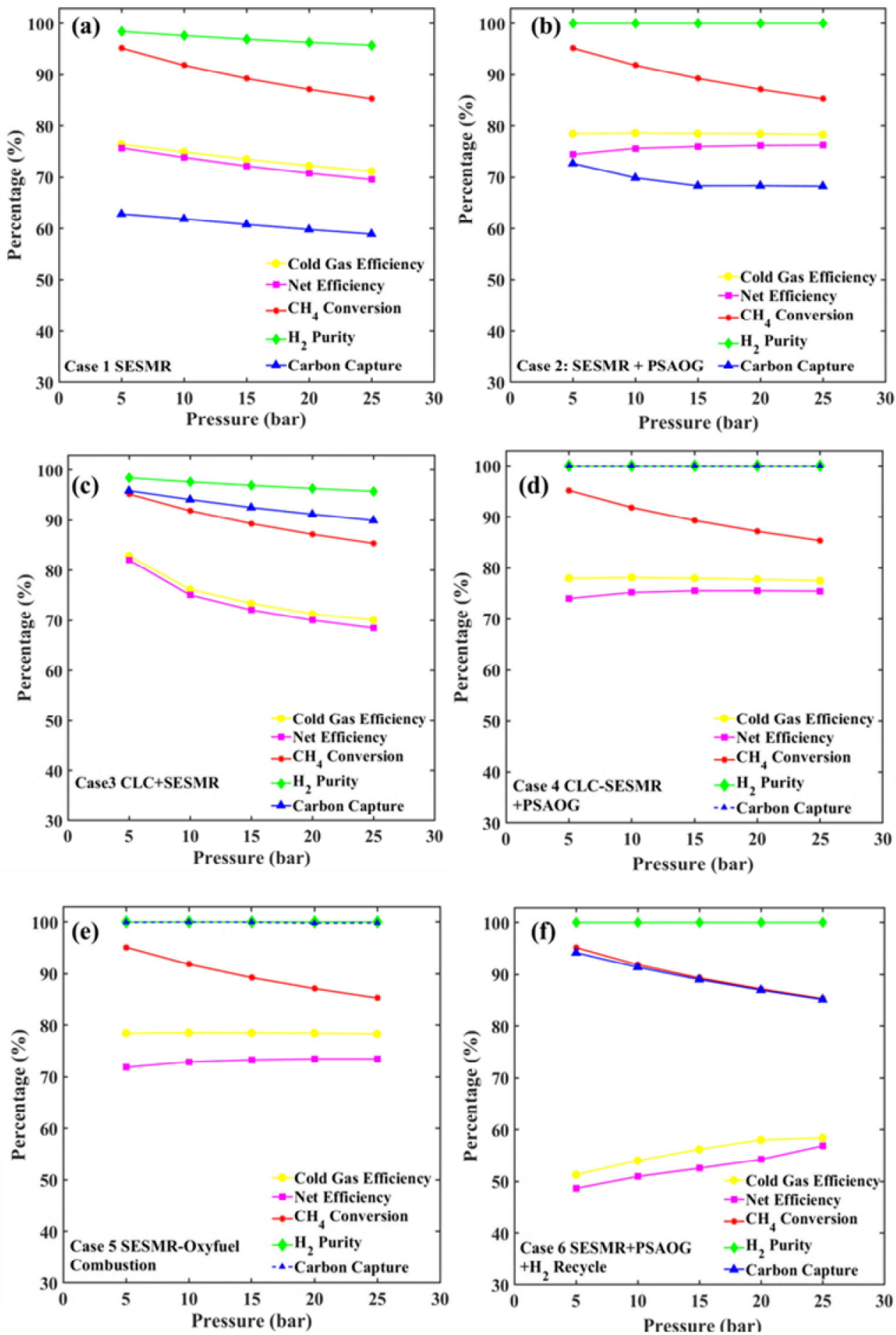

Figure 4 Process performance for different reforming pressures. (a) Case 1 SE-SMR, (b) Case 2 SESMR+PSAOG, (c) Case 3 CLC+SE-SMR, (d) Case 4 CLC+SE-SMR+PSAOG, (e) Case 5 SE$\mathrm{SMR}+\mathrm{Oxy}-$ fuel Combustion, (f) Case $6 \mathrm{SE}-\mathrm{SMR}+\mathrm{H}_{2}$ Recycle. 
In Case 2, the methane conversion is the same as Case 1. The hydrogen purity is nearly $100 \%$ for all pressures. Since the separation efficiency of the PSA is $95 \%$, the fuel feed in Case 2 is higher than that of Case 1 by the same factor. Because of the lower methane conversion ratio at a higher pressures, the PSAOG mass flow is higher and this reduces the fuel inlet flow rate by $28.8 \%$ when the reformer pressure is increased from 5 bar to 25 bar. On the other hand, the fuel feed is increased by $11.5 \%$ owing to the reduced methane conversion. As a result, the $\mathrm{CO}_{2}$ capture efficiency reduces at higher pressures by $6.2 \%$ due to the reduced methane conversion. The cold gas efficiency roughly remains constant with pressure as the reduction in the additional fuel is compensated by the increased fuel feed. However, the net efficiency is penalised and reduced at lower pressures owing to the pressurisation of the PSA upstream fluid to 25 bar. At 25 bar, the difference between cold gas efficiency and net efficiency is $2 \%$ points which increases to $4 \%$ points at 5 bar. Therefore, a 25 bar pressure is preferred in this case as this also eliminates the compressor needed to achieve 25 bar for the PSA.

Adding a CLC to Case 1 (Case 3) does not appear to affect the trend of methane conversion and hydrogen purity, which are the same as Case 1 . The $\mathrm{CO}_{2}$ capture efficiency declines with increasing pressure and a maximum capture of $95.9 \%$ is achieved at 5 bar. This is because the fuel supply required to meet the process utility is the smallest at lower pressure owing to the lower steam and fuel inlet flow rate at lower pressure. The cold gas efficiency is similar to Case 2 but lower by $0.5 \%$ points. This difference is due to the limitation of extracting heat with the current heat exchanger design and this could ideally be eliminated with the addition of heat exchangers. The difference between net efficiency and cold gas efficiency is $4 \%$ points at 5 bar, which reduces to $2 \%$ points at 25 bar. For Case 5 , the methane conversion is similar to Case 2 . The hydrogen purity and the $\mathrm{CO}_{2}$ capture efficiency are nearly $100 \%$. The cold gas efficiency is same as Case 2 for all pressures. However, the net efficiency is lower by $2.7 \%$ points than Case 2 for all pressures due to the auxiliary power consumption of an air separation unit.

In Case 6, the $\mathrm{CO}_{2}$ capture efficiency reaches $94.2 \%$ at 5 bar which is an increase of $21.5 \%$ points from Case 2. The $\mathrm{CO}_{2}$ capture efficiency reduces with increasing pressure owing to the increased PSAOG caused by the reduced methane conversion. Since this configuration does not add any additional infrastructure to capture the $\mathrm{CO}_{2}$, the capital cost of this case is expected to be lower. However, the increased $\mathrm{CO}_{2}$ capture efficiency comes with the trade-off in the net efficiency, which increases the operational cost. The cold gas efficiency is lower than Case 2 by $27.2 \%$ points at 5 bar whilst it is lower by $19.9 \%$ points at 25 bar. Therefore, a techno-economic assessment is essential to evaluate whether the increased $\mathrm{CO}_{2}$ capture efficiency at a lower capital cost outweighs the increased operational cost. 


\subsubsection{Effect of steam to carbon $(\mathrm{S} / \mathrm{C})$ ratio}

The effects of different S/C ratios on the process performance are shown in Figure 5. The increase in the reactant concentration favours the forward reaction according to Le Chatelier's principle in consequence increasing the methane conversion. The methane conversion increases from $67.3 \%$ to $85.3 \%$ for a corresponding increase in S/C ratio from 3 to 5 for all the cases when the reformer condition is 25 bar and $600{ }^{\circ} \mathrm{C}$. The hydrogen purity of Case 1 increases from $89.1 \%$ to $95.7 \%$ with the $\mathrm{S} / \mathrm{C}$ ratio. Since the methane conversion increases with the $\mathrm{S} / \mathrm{C}$ ratio, the fuel feed to meet $50 \mathrm{MW}_{\text {th }}$ plant capacity is reduced. However, the steam mass flow rate must increase to meet the increasing S/C ratio set point, which also increases the heat utility to the process, thereby raising the fuel supply by $3.3 \%$. The number of carbon moles in the reformer outlet stream reduces with the increase in $\mathrm{S} / \mathrm{C}$ ratio, owing to the increase in $\mathrm{CH}_{4}$ conversion and subsequent capture of $\mathrm{CO}_{2}$ by the sorbent. Since the reformer in-situ $\mathrm{CO}_{2}$ capture efficiency remains the same, the overall carbon capture efficiency has to increase with the S/C ratio. On the other hand, the additional fuel input required to meet the process heat utility also increases with S/C ratio by $3.3 \%$. However, the effect of the latter is minimal, consequently the $\mathrm{CO}_{2}$ capture efficiency increases at a higher $\mathrm{S} / \mathrm{C}$ ratio from $49.8 \%$ to $58.5 \%$. In addition, the cold gas efficiency also increases from $60.2 \%$ to $70.6 \%$ owing to the higher methane conversion. The difference between cold gas efficiency and the net efficiency increases from $1.5 \%$ points to $1.6 \%$ points when the $\mathrm{S} / \mathrm{C}$ increases from 3 to 5 .

When the PSA is added to the system (Case 2), the hydrogen purity of the product stream reaches nearly $100 \%$. The methane conversion is the same as Case 1 , which increases by $18 \%$ points when the S/C ratio changes from 3 to 5 . This also reduces the fuel feed by $21 \%$ in order to maintain the plant capacity, however, the steam flow increases by $31.5 \%$ to meet the higher S/C ratio target. Subsequently, the heat duty increases at higher S/C, which demands higher additional fuel use. The PSAOG itself can satisfy the heat utility of the process when the $\mathrm{S} / \mathrm{C}$ ratio is 3 and $26 \%$ of the fuel feed is required as an additional fuel to meet the heat load when $\mathrm{S} / \mathrm{C}$ ratio is 5 . It is worth highlighting that the heat content of PSAOG is surplus to the process heat utility when $\mathrm{S} / \mathrm{C}$ ratio is 3 , therefore, the carbon capture (1\% point) and the cold gas efficiency (1.1\% point) are lower compared with the $\mathrm{S} / \mathrm{C}$ ratio of 3.5. This also suggests that, at some $\mathrm{S} / \mathrm{C}$ ratio between 3 and 3.5 the PSAOG can exactly satisfy the heat utility of the process, offering slightly higher carbon capture and cold gas efficiency than the values presented for $\mathrm{S} / \mathrm{C}$ ratio of 3.5 . When the $\mathrm{S} / \mathrm{C}$ ratio increases from 3.5 to 5 , the $\mathrm{CO}_{2}$ capture efficiency and cold gas efficiency reduce from $68.3 \%$ to $67.6 \%$ and from $78.4 \%$ to $77.6 \%$, respectively. The difference between cold gas efficiency and net efficiency decreases with $\mathrm{S} / \mathrm{C}$ ratio from $2.5 \%$ points $(\mathrm{S} / \mathrm{C}=3)$ to $2 \%$ points $(\mathrm{S} / \mathrm{C}=5)$ which is not significant therefore the efficiency 
can be considered to be insensitive to the changes in S/C. The cold gas efficiency of Case 2 is higher than Case 1 by $7 \%$ points with a $\mathrm{CO}_{2}$ capture efficiency increase of $9.1 \%$ points when the $\mathrm{S} / \mathrm{C}$ ratio is 5 .

With the addition of CLC to Case 1 (Case 3), the carbon capture increases from $58.5 \%$ to $89.9 \%$ at $\mathrm{S} / \mathrm{C}=5$ without any impact on the hydrogen purity. The cold gas efficiency reduces by $0.6 \%$ points compared to Case 1 and is thus ensued by the current heat integration system. The penalty in the efficiency could theoretically be eliminated by increasing the number of heat exchangers and splitting the flow streams to minimise the exergy loss. The integration of CLC to Case 2 (Case 4) increases the carbon capture efficiency from $67.6 \%$ to nearly $100 \%$ and the hydrogen purity increased to near $100 \%$. The cold gas efficiency trend is similar to Case 2 with the negative offset of $0.6 \%$ points caused by the limitation of the current heat exchanger network design. Integration of oxy-combustion to Case 2 (Case 5) for calciner heat duty was shown to achieve nearly $100 \% \mathrm{CO}_{2}$ capture efficiency and hydrogen purity. The cold gas efficiency is same as Case 2 whilst the net efficiency is negatively offset by $2.7 \%$ points due to the power consumption of sir separation unit. It should be noted that the process is almost independent of S/C ratio when integrated with CLC+PSAOG (Case 4) and Oxy-combustion (Case 6). 

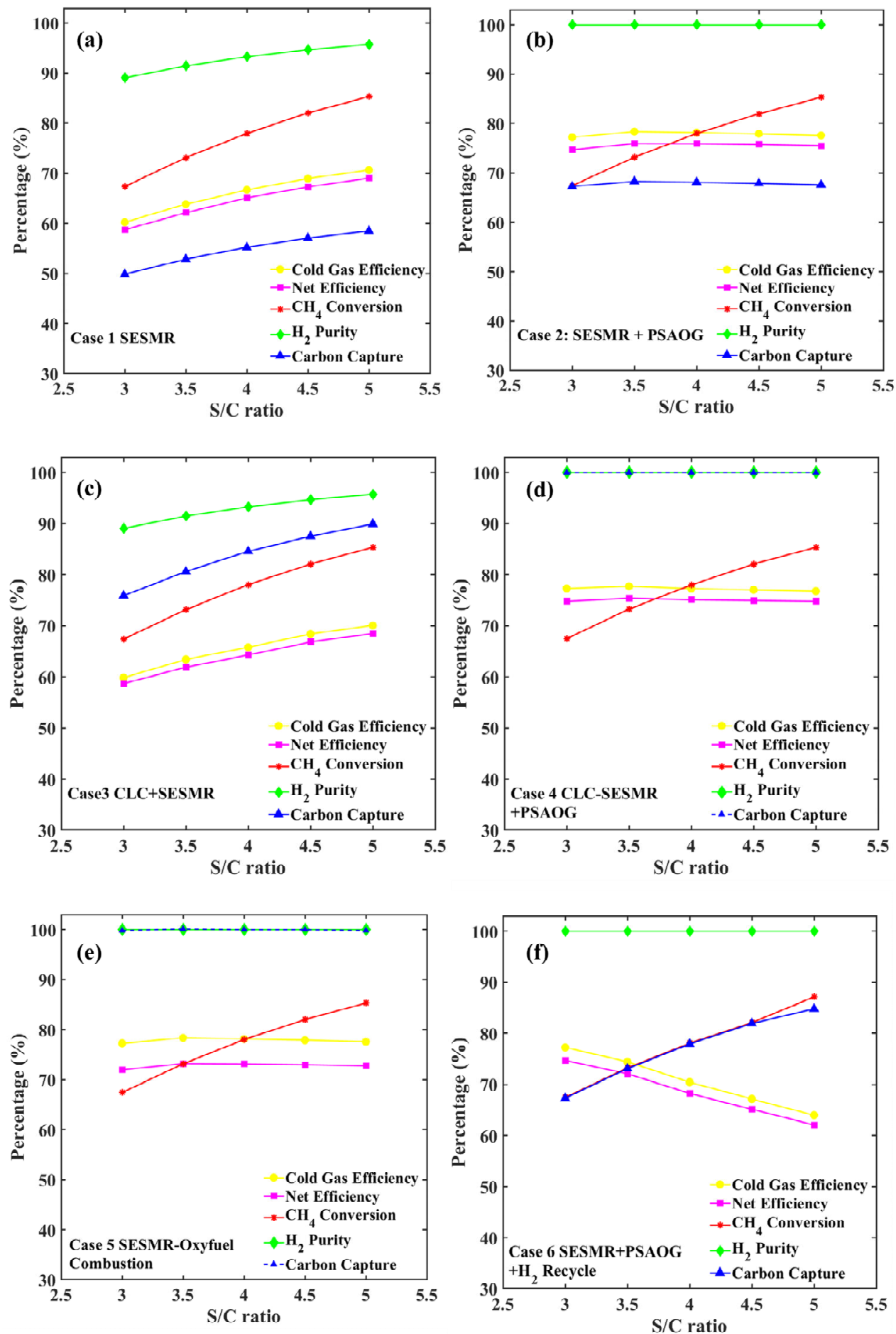

Figure 5 Process performance for different S/C ratios. (a) Case 1 SE-SMR, (b) Case 2 SE-SMR+PSAOG,

(c) Case 3 CLC+SE-SMR, (d) Case 4 CLC+SE-SMR+PSAOG, (e) Case 5 SE-SMR+Oxy-fuel Combustion, (f) Case $6 \mathrm{SE}-\mathrm{SMR}+\mathrm{H}_{2}$ Recycle. 
In Case 6, the hydrogen purity is $\sim 100 \%$ for all values of S/C ratio. Despite the increase of methane conversion at a higher $\mathrm{S} / \mathrm{C}$ ratio, the fuel feed also increases by $7.8 \%$ when the $\mathrm{S} / \mathrm{C}$ ratio increases from 3 to 5 to meet the plant capacity of $50 \mathrm{MWth}$ by satisfying the heat utility. The steam flow rate increases with the $\mathrm{S} / \mathrm{C}$ ratio by $79.9 \%$ thus the heat utility increases. The increase of the fuel feed at higher S/C ratio, where the methane conversion is higher, to meet the heat utility, also increases the sorbent flow given the calciner heat duty (36.8\%). Here, 18.3 MWth (36.6\% of the product hydrogen) is supplied as the additional fuel to meet the process heat demand for a $\mathrm{S} / \mathrm{C}$ ratio of 5 which is $37.7 \%$ higher than the additional heat supplied to Case 2. In consequence, the cold gas efficiency reduces by $13 \%$ points compared with Case 2 for a S/C ratio of 5 . In addition, the cold gas efficiency reduces from $77.3 \%$ to $64.6 \%$ when the $\mathrm{S} / \mathrm{C}$ ratio increases from 3 to 5 . The carbon capture efficiency on the other hand increases from $67.3 \%$ to $85.3 \%$ as the methane conversion is higher and the product hydrogen is supplied as an additional fuel.

\subsubsection{Effect of oxygen carriers}

In Case 3 and 4, it is necessary to ensure the fuel is fully converted in the FR and the oxidation of reduced oxygen carriers in the AR can provide enough heat for calciner in the SE-SMR. A sensitivity analysis of the molar ratio of $\mathrm{NiO}$ and $\mathrm{Fe}_{2} \mathrm{O}_{3}$ with fuel $\left(\mathrm{CH}_{4}, \mathrm{CO}\right.$ and $\left.\mathrm{H}_{2}\right)$ on the performance of Case 4 is investigated. Figure 6 indicates the relationship between $\mathrm{NiO}$ and $\mathrm{Fe}_{2} \mathrm{O}_{3} /$ fuel ratio and the performance of $\mathrm{FR}$. The $\mathrm{CO}_{2}$ concentration, carbon and hydrogen conversion of the FR increase with the increase of the both NiO and $\mathrm{Fe}_{2} \mathrm{O}_{3} /$ fuel ratio. When the $\mathrm{NiO}$ and $\mathrm{Fe}_{2} \mathrm{O}_{3} /$ fuel ratio reach the stoichiometric number of 4 and 9 respectively, the $\mathrm{CO}_{2}$ concentration, carbon and hydrogen conversion of the FR remain stable and close to $100 \%$.

Table 2 shows the performance of SE-SMR+PSA+CLC with $\mathrm{NiO} / \mathrm{Ni}$ and $\mathrm{Fe}_{2} \mathrm{O}_{3} / \mathrm{Fe}_{3} \mathrm{O}_{4}$ at the conditions of reformer at $600{ }^{\circ} \mathrm{C}, 25$ bar and $\mathrm{S} / \mathrm{C}=5$. The $\mathrm{CH}_{4}$ conversion of the reformer, cold gas efficiency and $\mathrm{H}_{2}$ purity of both processes are the same. The main difference is the fuel conversion in the $\mathrm{FR}$ and total $\mathrm{CO}_{2}$ capture. In the Ni-based oxygen carrier system, the maximum fuel conversion in the $\mathrm{FR}$ and total $\mathrm{CO}_{2}$ capture are $98.6 \%$ and $99.4 \%$ respectively, while that of Fe-CLC+SE-SMR+PSA are 100.0\% and 99.8\% respectively. It is clear that the Fe-CLC+SE-SMR+PSA does not have the thermodynamic limitation of the fuel conversion and is able to capture the almost all of the $\mathrm{CO}_{2}$ emissions from the $\mathrm{CH}_{4}$ compared to a Nibased process. 

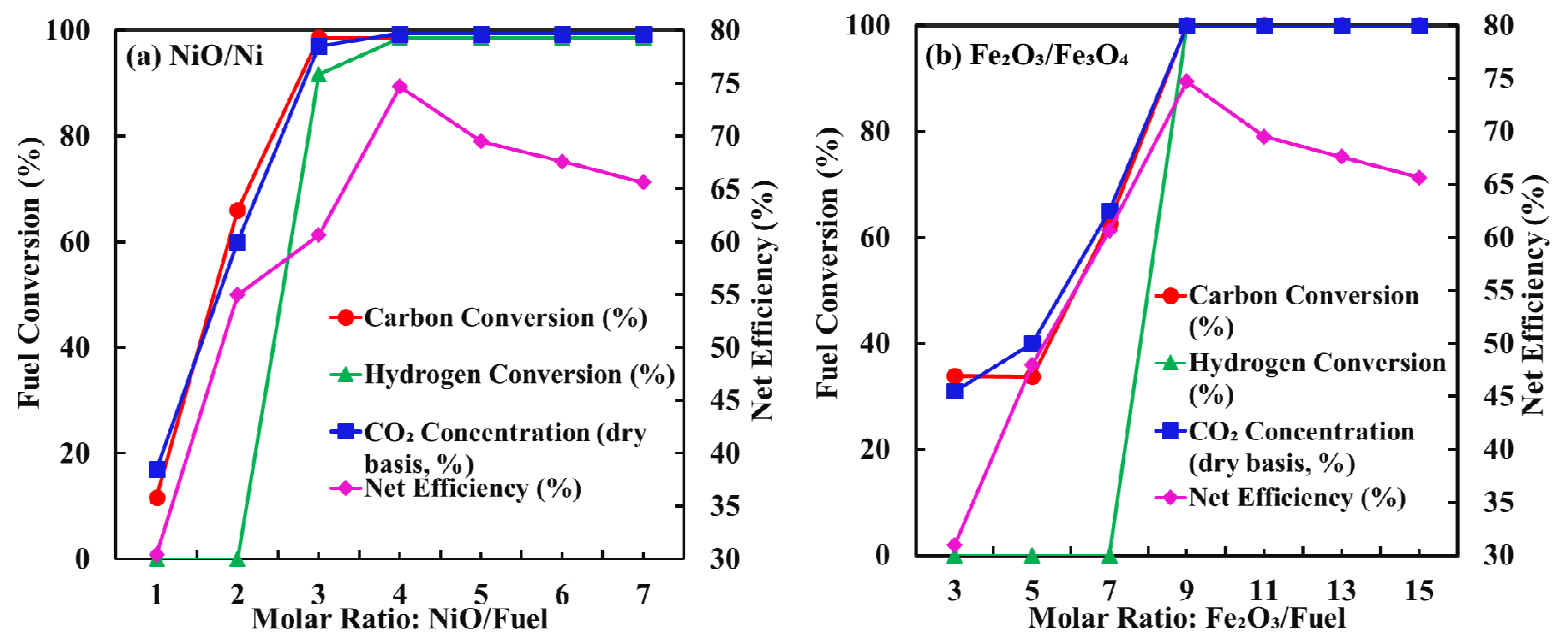

Figure 6 Effect of $\mathrm{NiO}$ and $\mathrm{Fe}_{2} \mathrm{O}_{3}$ /fuel on performance of FR in Case 4.

Table 2 The performance of SE-SMR+PSA+CLC with different oxygen carriers. (Reformer operated at $600{ }^{\circ} \mathrm{C}, 25$ bar and $\mathrm{S} / \mathrm{C}=5$ ).

\begin{tabular}{ccc}
\hline Performance & Ni-CLC+SE-SMR+PSA & Fe-CLC+SE-SMR+PSA \\
\hline $\mathrm{CH}_{4}$ conversion (\%) & 85.4 & 85.4 \\
$\mathrm{H}_{2}$ purity (\%) & 100 & 100 \\
$\mathrm{CO}_{2}$ capture (\%) & 99.4 & 99.8 \\
Fuel conversion in FR (\%) & 98.6 & 100.0 \\
Cold gas efficiency (\%) & 76.8 & 76.8 \\
Net efficiency (\%) & 74.7 & 74.8 \\
Mass flow rate of oxygen carriers to the FR $(\mathrm{kg} / \mathrm{s})$ & 89.1 & 119.5 \\
\hline
\end{tabular}

\subsection{Discussion}

In this work, we have proposed and compared six different SE-SMR systems for low-carbon and highpurity hydrogen production. The optimal operating conditions to achieve maximum $\mathrm{CO}_{2}$ capture and $\mathrm{H}_{2}$ purity from the parametric sensitivity analysis for each process is shown in Table 3. The conventional SESMR process (Case 1) can achieve a maximum $\mathrm{CO}_{2}$ capture efficiency of $63 \%$ with a $\mathrm{H}_{2}$ purity of $98 \%$ at $600{ }^{\circ} \mathrm{C}, 5$ bar and $\mathrm{S} / \mathrm{C}=5$. The $\mathrm{H}_{2}$ purity in Case 1 suffices for gas turbines, refinery processes and industrial boilers, but it does not meet the requirements of high-purity $\mathrm{H}_{2}$ applications such as fuel cells. The 
integration of a PSA with SE-SMR system can improve the $\mathrm{H}_{2}$ purity from $98 \%$ (Case 1 and 3) to nearly $100 \%$ (Case 2 and 4), and increase the total $\mathrm{CO}_{2}$ capture efficiency by 5-6\%. However, only Case 4 (SE$\mathrm{SMR}+\mathrm{PSA}+\mathrm{CLC}$ ) and Case 5 (SE-SMR+PSA+Oxy-fuel combustion) can achieve the highest $\mathrm{CO}_{2}$ capture efficiency $(\sim 100 \%)$ together with the highest $\mathrm{H}_{2}$ purity, but the net efficiency of Case 5 drops by $2.7 \%$ points compared to Case 2. The combustion of recycled $\mathrm{H}_{2}$ product with PSAOG to indirectly heat the calciner (Case 6) can generate a pure $\mathrm{H}_{2}$ product with $94.2 \% \mathrm{CO}_{2}$ capture (5 bar, $600{ }^{\circ} \mathrm{C}$ and $\mathrm{S} / \mathrm{C}=5$ ), but it has the lowest net efficiency, which increases the operational cost of the system. However, Case 6 does not have any additional components added for carbon capture, therefore the capital cost could be significantly lower than other alternatives to achieve $\sim 95 \%$ carbon capture efficiency. On the other hand, the thermodynamic optimal SE-SMR configuration for blue hydrogen production with $\sim 100 \% \mathrm{CO}_{2}$ capture efficiency is the configuration combining an integrated CLC with SE-SMR + PSA (Case 4), which is 2.7\% points higher in terms of net efficiency than that for Case 5. However, an economic study is needed to select the optimal configuration to achieve near $100 \%$ carbon capture efficiency.

Additionally, the best performance of Cases 2, 4, 5 and 6 is compared with literature results for SMR and SE-SMR processes integrated with $\mathrm{CO}_{2}$ capture technologies in Figure 7. It can be observed that only the CLC+SMR+PSA, SE-SMR+PSA+Oxy-fuel (Case 5) and SE-SMR+PSA+CLC systems (Case 4) are capable of achieving blue hydrogen production without sacrificing the cold gas and net efficiency of conventional SMR technology. Compared to the above processes, the configuration of SMR+MEA+PSA can only capture $90 \% \mathrm{CO}_{2}$ emission and the lower $\mathrm{CH}_{4}$ conversion and cold gas efficiency. It is also worth noting that the SE-SMR has a joint reformer and water-gas shift reactor and its $\mathrm{H}_{2}$ purity from the reformer to the PSA unit is much higher (98\%) than that of SMR, which means lower operational expenditure and a reduced energy penalty from the PSA system[50].

Currently, the overall technology readiness level (TRL) for CLC is estimated as TRL 6, and a large number of materials have been successfully tested in continuous operation in CLC facilities from $0.3 \mathrm{~kW}_{\text {th }}$ to 1 $\mathrm{MW}_{\text {th }}$ worldwide [51]. The current TRL for SE-SMR is at 4, and it has been intensively investigated from the batch-scale to the lab-scale reactors [8,10,11,52]. A $1.5 \mathrm{MW}_{\text {th }}$ SE-SMR pilot plant funded by UK Department for Business, Energy and Industrial Strategy's Energy Innovation Programme will be constructed at Cranfield University to identify pathways to accelerate the development of SE-SMR technology [53]. 
Table 3 Optimal design space for each SE-SMR process.

\begin{tabular}{|c|c|c|c|c|c|c|}
\hline $\begin{array}{c}\text { Case } \\
\text { No. }\end{array}$ & $\begin{array}{c}\text { Reforming } \\
\text { temperature } \\
\left({ }^{\circ} \mathbf{C}\right)\end{array}$ & $\begin{array}{l}\text { Reforming } \\
\text { pressure } \\
\text { (bar) }\end{array}$ & $\mathrm{S} / \mathrm{C}$ & $\begin{array}{c}\mathrm{CO}_{2} \\
\text { capture } \\
(\%)\end{array}$ & $\begin{array}{c}\mathrm{H}_{2} \\
\text { purity } \\
(\%)\end{array}$ & $\begin{array}{c}\text { Net } \\
\text { efficiency }\end{array}$ \\
\hline 1 & $600-650$ & 5 & 5 & 63 & 98 & 76 \\
\hline 2 & $<650$ & $\begin{array}{c}5 \text { (maximises } \mathrm{CO}_{2} \\
\text { capture } \\
\text { efficiency) } \\
25 \text { (maximises } \\
\text { efficiency) }\end{array}$ & Independent & 69 & 100 & 75 \\
\hline 3 & $600-650$ & 5 & 5 & 95 & 98 & 72 \\
\hline 4 & $<650$ & $\begin{array}{l}25 \text { (eliminates a } \\
\text { compressor, } \\
\text { efficiency change } \\
\text { is negligible) }\end{array}$ & Independent & 100 & 100 & 76 \\
\hline 5 & $<650$ & $\begin{array}{l}25 \text { (eliminates a } \\
\text { compressor, } \\
\text { efficiency change } \\
\text { is negligible) }\end{array}$ & Independent & 100 & 100 & 74 \\
\hline 6 & $<650$ & $\begin{array}{c}5 \text { (maximises } \mathrm{CO}_{2} \\
\text { capture } \\
\text { efficiency) } \\
25 \text { (maximises } \\
\text { efficiency) }\end{array}$ & $\begin{array}{l}5 \text { (maximises } \\
\mathrm{CO}_{2} \text { capture } \\
\text { efficiency) } \\
3 \text { (maximises } \\
\text { efficiency) }\end{array}$ & 87 & 100 & 62 \\
\hline
\end{tabular}

Although the development in CLC and SE-SMR is promising, there are some obvious challenges with the concept of SE-SMR combined with CLC. Firstly, the heat transfer between the AR to the calciner through the fluidised-bed heat exchanger or heat pipes is at a very early stage. There are some undergoing projects, such as ANICA [54] and HyPER[55], are investigating the performance of indirectly heated calciner at pilot-scale. More work is required to design and test the feasibility of a calciner thermally coupled with the AR using tubes or pipes without influencing the fluidisation and circulation of sorbents and oxygen carriers. Secondly, the different lifetimes and performance of sorbents and oxygen carriers may increase the maintenance and add some operational challenges and costs. Moreover, while there are many economic 
evaluations of SMR with carbon capture technologies, there is no available information for the SESMR+PSA+CLC and SE-SMR+Oxy-fuel combustion systems. Thus, a detailed economic assessment is required to fully understand the potential of this concept at larger scales.

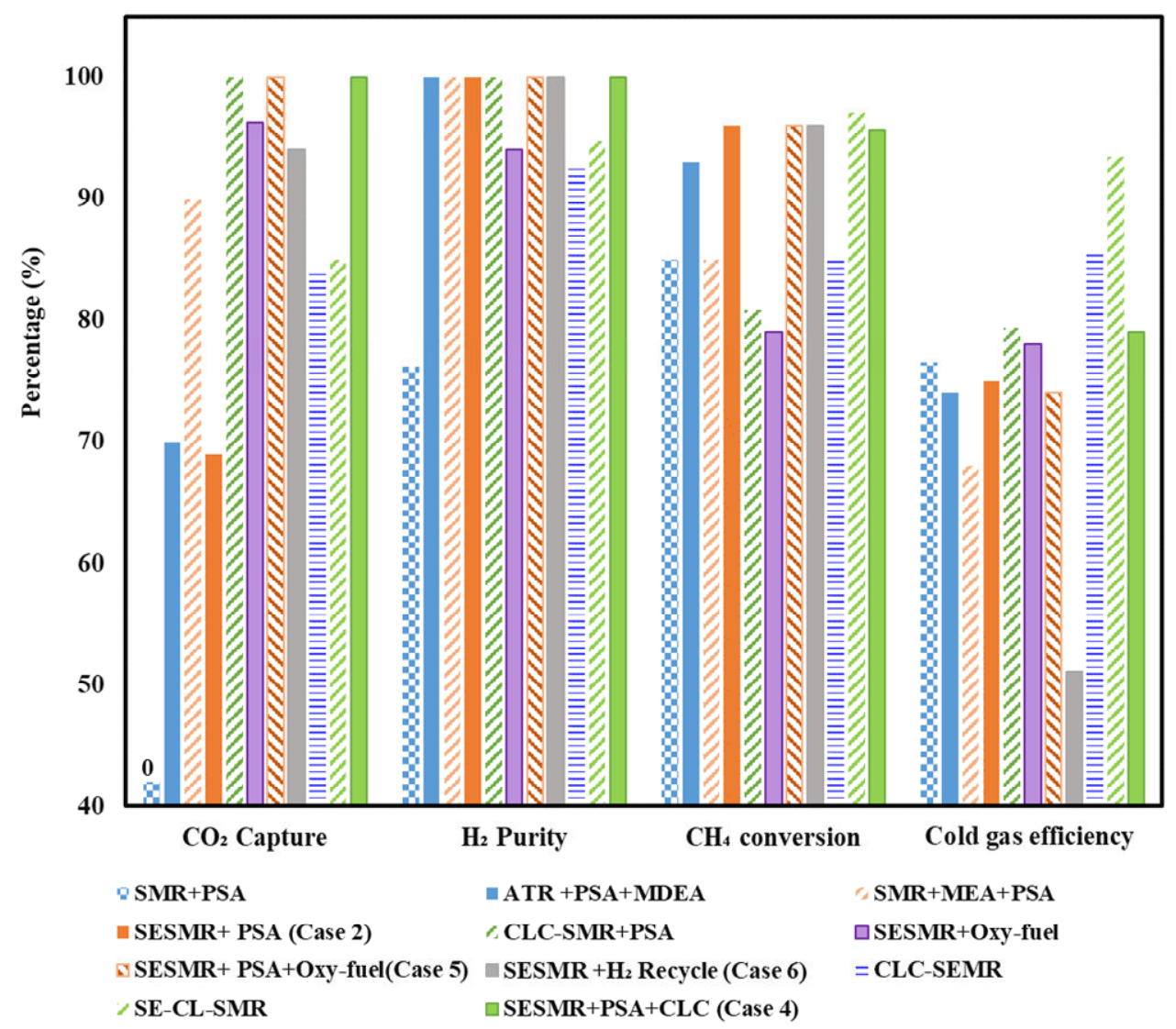

Figure 7 Comparison of proposed SE-SMR+PSA+CLC with the reported steam methane reforming processes in literature: SMR+PSA [17], ATR+PSA+MDEA [56,57], SMR+MEA+PSA [58], CLC+SMR+PSA [39], SE-SMR+Oxy-fuel [59], CLC+SE-SMR [26], SE-CL-SMR [60].

\section{Conclusions}

This work evaluates the competitiveness of six different sorption enhanced steam methane reforming (SESMR) configurations for clean hydrogen production. A thermodynamic analysis using Aspen Plus with a detailed heat exchanger modelling to recover the waste heat from the process respecting the second-law of thermodynamic, was used to evaluate the process performance of methane conversion, $\mathrm{CO}_{2}$ capture efficiency, $\mathrm{H}_{2}$ purity, maximum cold gas efficiency and net efficiency. 
A parametric analysis was conducted to optimise operating process conditions considering the effects of reforming temperature, reforming pressure and $\mathrm{S} / \mathrm{C}$ ratio on the process performance. The results indicate that the proposed cases in this work can provide flexible options for low-carbon hydrogen production based on the costs and demand of $\mathrm{CO}_{2}$ reduction. The process of SE-SMR+PSA+CLC can realise nearly $100 \%$ $\mathrm{CO}_{2}$ capture efficiency with the highest net efficiency of $75.5 \%$ in terms of near pure hydrogen production at a reformer temperature of $600{ }^{\circ} \mathrm{C}$, a reformer pressure of $25 \mathrm{bar}$, and a $\mathrm{S} / \mathrm{C}=5$, whilst the integration of oxy-combustion achieves the same $\mathrm{CO}_{2}$ capture efficiency with nearly $100 \%$ hydrogen purity but with a $2.7 \%$ points penalty in the net efficiency. On the other hand, Case 6 where a proportion of the $\mathrm{H}_{2}$ is recycled to provide heat for the calcination is able to achieve $94.2 \%$ carbon capture efficiency with a trade-off in the process efficiency.

In addition, utilisation of the PSAOG in Cases 2, 4 and 5 makes the $\mathrm{CO}_{2}$ capture efficiency and cold gas efficiency independent of $\mathrm{S} / \mathrm{C}$, which could offer a large operational flexibility with a higher efficiency. The SE-SMR with the PSAOG case (Case 2) can be designed not to need additional fuel to meet the process heat utility when the $\mathrm{S} / \mathrm{C}$ is between 3-3.5.

\section{Acknowledgments}

YYL would like to acknowledge the financial support from the Cranfield University Energy and Power research bursary.

\section{References}

[1] IEA. The Future of Hydrogen. 2019. doi:10.1787/1e0514c4-en.

[2] Khojasteh Salkuyeh Y, Saville BA, MacLean HL. Techno-economic analysis and life cycle assessment of hydrogen production from natural gas using current and emerging technologies. Int. J. Hydrogen. Energy 2017;42:18894-909. doi:10.1016/j.ijhydene.2017.05.219.

[3] Clough PT, Boot-Handford ME, Zheng L, Zhang Z, Fennell PS. Hydrogen production by sorption enhanced steam reforming (SESR) of biomass in a fluidised-bed reactor using combined multifunctional particles. Materials (Basel) 2018;11. doi:10.3390/ma11050859.

[4] Rostrup-Nielsen JR. Catalytic Steam Reforming, 1984, p. 1-117. doi:10.1007/978-3-642- 
93247-2_1.

[5] Williams R. Hydrogen production. 1930. US1938202A

[6] Goria E, Gia P, Retaick WB. United States Patent Office 3,108,857 METHOD FOR THE PROB) JCTION OF HYDROGEN. 1963.

[7] Ortiz AL, Harrison DP. Hydrogen production using sorption-enhanced reaction. Ind. Eng. Chem. Res., vol. 40, 2001, p. 5102-9. doi:10.1021/ie001009c.

[8] Johnsen K, Ryu HJ, Grace JR, Lim CJ. Sorption-enhanced steam reforming of methane in a fluidized bed reactor with dolomite as $\mathrm{CO}_{2}$-acceptor. Chem Eng Sci 2006;61:1195-202. doi:10.1016/j.ces.2005.08.022.

[9] García-Lario AL, Aznar M, Martinez I, Grasa GS, Murillo R. Experimental study of the application of a $\mathrm{NiO} / \mathrm{NiAl}_{2} \mathrm{O}_{4}$ catalyst and a CaO-based synthetic sorbent on the Sorption Enhanced Reforming process. Int. J. Hydrogen. Energy. 2015;40:219-32. doi:10.1016/j.ijhydene.2014.10.033.

[10] Arstad B, Prostak J, Blom R. Continuous hydrogen production by sorption enhanced steam methane reforming (SE-SMR) in a circulating fluidized bed reactor: Sorbent to catalyst ratio dependencies. Chem Eng J 2012;189-190:413-21. doi:10.1016/j.cej.2012.02.057.

[11] Li ZS, Cai NS, Yang JB. Continuous production of hydrogen from sorption-enhanced steam methane reforming in two parallel fixed-bed reactors operated in a cyclic manner. Ind Eng Chem Res 2006;45:8788-93. doi:10.1021/ie061010x.

[12] Di Giuliano A, Gallucci K, Kazi SS, Giancaterino F, Di Carlo A, Courson C, et al. Development of Ni- and CaO-based mono- and bi-functional catalyst and sorbent materials for Sorption Enhanced Steam Methane Reforming: Performance over 200 cycles and attrition tests. Fuel Process Technol 2019;195:106160. doi:10.1016/j.fuproc.2019.106160. 
[13] Di Felice L, Kazi SS, Sørby MH, Martinez I, Grasa G, Maury D, et al. Combined sorbent and catalyst material for sorption enhanced reforming of methane under cyclic regeneration in presence of $\mathrm{H}_{2} \mathrm{O}$ and $\mathrm{CO}_{2}$. Fuel Process Technol 2019;183:35-47. doi:10.1016/j.fuproc.2018.10.012.

[14] Harrison DP. Sorption-enhanced hydrogen production: A review. Ind. Eng. Chem. Res., vol. 47, American Chemical Society; 2008, p. 6486-501. doi:10.1021/ie800298z.

[15] Di Giuliano A, Gallucci K. Sorption enhanced steam methane reforming based on nickel and calcium looping: a review. Chem Eng Process - Process Intensif 2018;130:240-52. doi:10.1016/j.cep.2018.06.021.

[16] Broda M, Manovic V, Imtiaz Q, Kierzkowska AM, Anthony EJ, Müller CR. High-purity hydrogen via the sorption-enhanced steam methane reforming reaction over a synthetic CaO-based sorbent and a Ni catalyst. Environ Sci Technol 2013;47:6007-14. doi:10.1021/es305113p.

[17] Ochoa-Fernández E, Haugen G, Zhao T, Rønning M, Aartun I, Børresen B, et al. Process design simulation of $\mathrm{H}_{2}$ production by sorption enhanced steam methane reforming: evaluation of potential $\mathrm{CO}_{2}$ acceptors. Green Chem 2007;9:654-62. doi:10.1039/B614270B.

[18] Mattisson T, Lyngfelt A, Leion H. Chemical-looping with oxygen uncoupling for combustion of solid fuels. Int $\mathrm{J}$ Greenh Gas Control 2009;3:11-9. doi:10.1016/J.IJGGC.2008.06.002.

[19] Mukherjee S, Kumar P, Yang A, Fennell P. Energy and exergy analysis of chemical looping combustion technology and comparison with pre-combustion and oxy-fuel combustion technologies for $\mathrm{CO}_{2}$ capture. J Environ Chem Eng 2015;3:2104-14. 
doi:10.1016/J.JECE.2015.07.018.

[20] Bui M, Adjiman CS, Bardow A, Anthony EJ, Boston A, Brown S, et al. Carbon capture and storage (CCS): The way forward. Energy Environ Sci 2018;11:1062-176. doi:10.1039/c7ee02342a.

[21] Ishida M, Jin H. A new advanced power-generation system using chemical-looping combustion. Energy 1994;19:415-22. doi:10.1016/0360-5442(94)90120-1.

[22] Lyngfelt A, Leckner B, Mattisson T. A fluidized-bed combustion process with inherent $\mathrm{CO}_{2}$ separation; application of chemical-looping combustion. Chem Eng Sci 2001;56:3101-13. doi:10.1016/S0009-2509(01)00007-0.

[23] Rydén M, Lyngfelt A. Using steam reforming to produce hydrogen with carbon dioxide capture by chemical-looping combustion. Int. J. Hydrogen. Energy. 2006;31:1271-83. doi:10.1016/J.IJHYDENE.2005.12.003.

[24] Ortiz M, Gayán P, De Diego LF, García-Labiano F, Abad A, Pans MA, et al. Hydrogen production with $\mathrm{CO}_{2}$ capture by coupling steam reforming of methane and chemical-looping combustion: Use of an iron-based waste product as oxygen carrier burning a PSA tail gas. J. Power Sources, vol. 196, Elsevier; 2011, p. 4370-81. doi:10.1016/j.jpowsour.2010.09.101.

[25] Zhu L, Fan J. Thermodynamic analysis of $\mathrm{H}_{2}$ production from $\mathrm{CaO}$ sorption-enhanced methane steam reforming thermally coupled with chemical looping combustion as a novel technology. Int J Energy Res 2015;39:356-69. doi:10.1002/er.3248.

[26] Zhu L, Li L, Fan J. A modified process for overcoming the drawbacks of conventional steam methane reforming for hydrogen production: Thermodynamic investigation. Chem Eng Res Des 2015;104:792-806. doi:10.1016/j.cherd.2015.10.022. 
[27] Alam S, Kumar JP, Rani KY, Sumana C. Self-sustained process scheme for high purity hydrogen production using sorption enhanced steam methane reforming coupled with chemical looping combustion. J Clean Prod 2017;162:687-701. doi:10.1016/j.jclepro.2017.05.136.

[28] Abanades JC, Murillo R, Fernandez JR, Grasa G, Martínez I. New CO2 capture process for hydrogen production combining $\mathrm{Ca}$ and $\mathrm{Cu}$ chemical loops. Environ Sci Technol 2010;44:6901-4. doi:10.1021/es101707t.

[29] Antzara A, Heracleous E, Lemonidou AA. Energy efficient sorption enhanced-chemical looping methane reforming process for high-purity $\mathrm{H}_{2}$ production: Experimental proof-ofconcept. Appl Energy 2016;180:457-71. doi:10.1016/j.apenergy.2016.08.005.

[30] Ma J, Mei D, Peng W, Tian X, Ren D, Zhao H. On the high performance of a core-shell structured $\mathrm{CaO}-\mathrm{CuO} / \mathrm{MgO} @ \mathrm{~A} 12 \mathrm{O} 3$ material in calcium looping integrated with chemical looping combustion (CaL-CLC). Chem. Eng. J. 2019;368:504-12. doi:10.1016/j.cej.2019.02.188.

[31] Martini M, van den Berg A, Gallucci F, van Sint Annaland M. Investigation of the process operability windows for $\mathrm{Ca}-\mathrm{Cu}$ looping for hydrogen production with $\mathrm{CO} 2$ capture. Chem Eng J 2016;303:73-88. doi:10.1016/j.cej.2016.05.135.

[32] Martínez I, Fernández JR, Martini M, Gallucci F, van Sint Annaland M, Romano MC, et al. Recent progress of the $\mathrm{Ca}-\mathrm{Cu}$ technology for decarbonisation of power plants and carbon intensive industries. Int. J. Greenh. Gas. Control. 2019;85:71-85. doi:10.1016/j.ijggc.2019.03.026.

[33] Lyngfelt A. Oxygen carriers for chemical-looping combustion. Elsevier; 2015. doi:10.1016/B978-0-85709-243-4.00011-2. 
[34] Idziak K, Czakiert T, Krzywanski J, Zylka A, Kozlowska M, Nowak W. Safety and environmental reasons for the use of $\mathrm{Ni}-, \mathrm{Co}-, \mathrm{Cu}-, \mathrm{Mn}-$ and Fe-based oxygen carriers in CLC/CLOU applications: An overview. Fuel 2020;268:117245. doi:10.1016/j.fuel.2020.117245.

[35] Mukherjee S, Kumar P, Yang A, Fennell P. A systematic investigation of the performance of copper-, cobalt-, iron-, manganese- and nickel-based oxygen carriers for chemical looping combustion technology through simulation models. Chem. Eng. Sci. 2015;130:7991. doi:10.1016/j.ces.2015.03.009.

[36] Shen L, Wu J, Xiao J, Song Q, Xiao R. Chemical-looping combustion of biomass in a 10 kWth reactor with iron oxide as an oxygen carrier. Energy and Fuels 2009;23:2498-505. doi:10.1021/ef900033n.

[37] Tong A, Bayham S, Kathe M V., Zeng L, Luo S, Fan LS. Iron-based syngas chemical looping process and coal-direct chemical looping process development at Ohio State University. Appl Energy 2014;113:1836-45. doi:10.1016/j.apenergy.2013.05.024.

[38] Bidwe AR, Mayer F, Hawthorne C, Charitos A, Schuster A, Scheffknecht G. Use of ilmenite as an oxygen carrier in chemical looping combustion-batch and continuous dual fluidized bed investigation. Energy Procedia, vol. 4, Elsevier Ltd; 2011, p. 433-40. doi:10.1016/j.egypro.2011.01.072.

[39] Stenberg V, Rydén M, Mattisson T, Lyngfelt A. Exploring novel hydrogen production processes by integration of steam methane reforming with chemical-looping combustion (CLC-SMR) and oxygen carrier aided combustion (OCAC-SMR). Int. J. Greenh. Gas. Control. 2018;74:28-39. doi:10.1016/j.ijggc.2018.01.008.

[40] Reitza M, Junka M, Ströhlea J, Epplea B. Design and erection of a $300 \mathrm{kWth}$ indirectly 
heated carbonate looping test facility. Energy Procedia, vol. 63, Elsevier Ltd; 2014, p. 2170 7. doi:10.1016/j.egypro.2014.11.236.

[41] Junk M, Reitz M, Ströhle J, Epple B. Technical and Economical Assessment of the Indirectly Heated Carbonate Looping Process. J. Energy. Resour. Technol. 2016;138. doi:10.1115/1.4033142.

[42] Hoeftberger D, Karl J. The indirectly heated carbonate looping process for $\mathrm{CO}_{2}$ capture A concept with heat pipe heat exchanger. J. Energy. Resour. Technol. Trans. ASME 2016;138. doi:10.1115/1.4033302.

[43] Reitz M, Junk M, Ströhle J, Epple B. Design and operation of a $300 \mathrm{kWth}$ indirectly heated carbonate looping pilot plant. Int. J. Greenh. Gas. Control. 2016;54:272-81. doi:10.1016/j.ijggc.2016.09.016.

[44] Arias B, Diego ME, Abanades JC, Lorenzo M, Diaz L, Martínez D, et al. Demonstration of steady state $\mathrm{CO}_{2}$ capture in a $1.7 \mathrm{MW}$ th calcium looping pilot. Int. J. Greenh. Gas. Control. 2013;18:237-45. doi:10.1016/j.ijggc.2013.07.014.

[45] Arias B, Diego ME, Méndez A, Alonso M, Abanades JC. Calcium looping performance under extreme oxy-fuel combustion conditions in the calciner. Fuel 2018;222:711-7. doi:10.1016/j.fuel.2018.02.163.

[46] Pashchenko D. Thermodynamic equilibrium analysis of combined dry and steam reforming of propane for thermochemical waste-heat recuperation. Int. J. Hydrogen. Energy. 2017;42:14926-35. doi:10.1016/j.ijhydene.2017.04.284.

[47] Pashchenko D. Experimental study of methane reforming with products of complete methane combustion in a reformer filled with a nickel-based catalyst. Energy Convers Manag 2019;183:159-66. doi:10.1016/j.enconman.2018.12.102. 
[48] Fan Y, Yao JG, Zhang Z, Sceats M, Zhuo Y, Li L, et al. Pressurized calcium looping in the presence of steam in a spout-fluidized-bed reactor with DFT analysis. Fuel Process Technol 2018;169:24-41. doi:10.1016/j.fuproc.2017.09.006.

[49] Tranier J-P, Dubettier R, Perrin N, Air Liquide. Air Separation Unit for Oxy-Coal Combustion Systems. 1st Int. Oxyfuel Combust. Conf., 2009.

[50] Waldron WE, Sircar S. Parametric Study of a Pressure Swing Adsorption Process. vol. 6. 2000.

[51] Yan Y, Mattisson T, Moldenhauer P, Anthony EJ, Clough PT. Applying machine learning algorithms in estimating the performance of heterogeneous, multi-component materials as oxygen carriers for chemical-looping processes. Chem. Eng. J. 2020;387:124072. doi:10.1016/j.cej.2020.124072.

[52] Mays J. One Step Hydrogen Generation Through Sorption Enhanced Reforming. Golden, CO (United States): 2015. doi:10.2172/1373949.

[53] Low-carbon hydrogen - international project examines new technology https://www.cranfield.ac.uk/press/news-2020/low-carbon-hydrogen-international-projectexamines-new-technology (accessed March 31, 2020).

[54] ANICA - ACT n.d. http://www.act-ccs.eu/anica (accessed June 17, 2020).

[55] Phase 1 SBRI Hydrogen Supply Competition Bulk Hydrogen Production by Sorbent Enhanced Steam Reforming (HyPER) Project Executive Summaryhttps://assets.publishing.service.gov.uk/government/uploads/system/uploads/attachment_d ata/file/866373/Phase_1_-_Cranfield_-_HyPER.pdf

[56] Halabi MH, de Croon MHJM, van der Schaaf J, Cobden PD, Schouten JC. Modeling and analysis of autothermal reforming of methane to hydrogen in a fixed bed reformer. Chem 
Eng J 2008;137:568-78. doi:10.1016/j.cej.2007.05.019.

[57] Editors G, Walmsley TG, Su R, Cormos A-M, Szima S, Fogarasi S, et al. Economic Assessments of Hydrogen Production Processes Based on Natural Gas Reforming with Carbon Capture. vol. 70, 2018. doi:10.3303/CET1870206.

[58] Tarun CB, Croiset E, Douglas PL, Gupta M, Chowdhury MHM. Techno-economic study of $\mathrm{CO}_{2}$ capture from natural gas based hydrogen plants. Int. J. Greenh. Gas. Control. 2007;1:55-61. doi:10.1016/S1750-5836(07)00036-9.

[59] Tzanetis KF, Martavaltzi CS, Lemonidou AA. Comparative exergy analysis of sorption enhanced and conventional methane steam reforming. Int. J. Hydrogen. Energy, vol. 37, 2012, p. 16308-20. doi:10.1016/j.ijhydene.2012.02.191.

[60] Antzara A, Heracleous E, Bukur DB, Lemonidou AA. Thermodynamic analysis of hydrogen production via chemical looping steam methane reforming coupled with in situ $\mathrm{CO}_{2}$ capture. Energy Procedia 2014;63:6576-89. doi:10.1016/j.egypro.2014.11.694. 